\title{
Absence of specific alternatively spliced exon of CD44 in macrophages prevents colitis
}

\author{
BM Wittig ${ }^{1,10}$, R Sabat ${ }^{2,10}$, P Holzlöhner1 ${ }^{1}$ E Witte-Händel ${ }^{2}$, K Heilmann' ${ }^{1}, \mathrm{~K}_{\text {Witte }}{ }^{2}$, J Triebus ${ }^{2}$, \\ A Tzankov ${ }^{3}$, JD Laman ${ }^{4}$, B Bokemeyer ${ }^{5}, \mathrm{~L}_{\text {Terracciano }}^{3}$, C Schwärzler ${ }^{6}, \mathrm{H} \mathrm{Kohler}^{7}, \mathrm{R} \mathrm{Volkmer}^{8}$, \\ C Loddenkemper ${ }^{9}, \mathrm{~K}_{\text {Wolk }}^{2}$, U Hoffmann ${ }^{1}$ and U Günthert ${ }^{3}$
}

CD44 is a transmembrane molecule appearing in numerous isoforms generated by insertions of alternatively spliced variant exons $(C D 44 v)$ and having various binding partners. CD44v7 on T cells was proposed to promote colitis by preventing T-cell apoptosis. Here we demonstrate that Cd44v7-deficient T cells - like Cd44 wild-type (Cd44 $\left.{ }^{W T}\right) \mathrm{T}$ cells provoked disease in two different colitis models: the model induced by CD4 ${ }^{+}$CD45RB ${ }^{\text {high }}$ T-cell transfer into Rag2deficient mice and a new model based on ovalbumin (OVA)-specific T-cell transfer into Rag-sufficient, OVA-challenged mice. In contrast, CD44v7 absence on macrophages in recipient mice prevented colitis. Prevention was associated with the downregulation of signal transducer and activator of transcription 3 (STAT3)-activating and Foxp3-counteracting interleukin-6 (IL-6), lower numbers of phospho-STAT3-containing lymphocytes, and higher Foxp3 ${ }^{+}$T-cell counts in the $^{-}$ colon. Consequently, the protected colons showed lower IL-12, IL-1 $\beta$ expression, and decreased interferon- $\gamma$ levels. Importantly, stimulation of T cells by Cd44v7-deficient macrophages induced upregulation of Foxp3 in vitro, while cotransfer of $C d 44^{W T}$ macrophages into Cd44v7-deficient mice reduced Foxp3 ${ }^{+}$T-cell counts and caused colitis. Accordingly, the CD44v7 ligand osteopontin, whose levels were elevated in Crohn's disease, specifically induced IL-6 in human monocytes, a cytokine also increased in these patients. We suggest macrophage-specific targeting of the CD44v7 pathway as a novel therapeutic option for Crohn's disease.

\section{INTRODUCTION}

The human gastrointestinal tract with its $450 \mathrm{~m}^{2}$ surface is the largest barrier of the organism towards the environment. It is in permanent contact with food and the intestinal microbiota. A well-balanced system of immune attack and immune tolerance mechanisms in response to these antigens is necessary for the maintenance of gut homeostasis. The disruption of this balance causes either the systemic invasion of microbes or harmful host immune stimulation damaging intestinal tissue. ${ }^{1-3}$ The latter seems to be the case in inflammatory bowel diseases (IBD). Here, macrophages and $\mathrm{T}$ cells accumulate in the lamina propria of the intestinal tract, activate each other, destroy the regular architecture of the gut wall, and disturb the intestinal function. Several molecules expressed by macrophages and $\mathrm{T}$ cells including interleukin-12 (IL-12), interferon- $\gamma$, IL-10, and Foxp3 are critical for the intestinal balance between immune attack and tolerance. ${ }^{4-6}$ Our previous studies also suggested a crucial role of CD44 in gastrointestinal inflammation. ${ }^{7,8}$

CD44 is a transmembrane molecule with multiple, in part poorly understood functions. ${ }^{9-12}$ The standard isoform (CD44s) is composed of products of exons $1-5$ and 16-20 and is expressed by most cell types, where it regulates proliferation and apoptosis. However, numerous further isoforms of CD44 are generated by insertions of different variable regions into a single site of its extracellular domain. ${ }^{9-12}$ These variable regions arise from alternative splicing of up to

${ }^{1}$ Medical Clinic 1 (Gastroenterology/Infectiology/Rheumatology), University Medicine Charité, Berlin, Germany. ${ }^{2}$ Interdisciplinary Group of Molecular Immunopathology and Psoriasis Research and Treatment Center, Dermatology/Medical Immunology, University Medicine Charité, Berlin, Germany. ${ }^{3}$ Institute of Pathology, University Hospital Basel, Basel, Switzerland. ${ }^{4}$ Department of Neuroscience, University Medical Center Groningen, Groningen, The Netherlands. ${ }^{5}$ Gastroenterology Practice, Minden, Germany. ${ }^{6}$ Federal Polytechnic University Lausanne (Flow Cytometry Core Facility), Lausanne, Switzerland. ${ }^{7}$ Friedrich Miescher Institute for Biomedical Research, Basel, Switzerland. ${ }^{8}$ Institute for Medical Immunology, University Medicine Charité, Berlin, Germany and ${ }^{9}$ Institute of Pathology, University Medicine Charité, Berlin, Germany. Correspondence: R Sabat (robert.sabat@charite.de) or U Günthert (ursula.guenthert@unibas.ch)

${ }^{10}$ These authors contributed equally to this work and are co-first authors. 
ten additional, that is, variant exons ( $v 1$ to $v 10$ corresponding to exons 6 to 15 of the gene) (Supplementary Figure S1 online). In contrast to $\mathrm{CD} 44 \mathrm{~s}$, the $\mathrm{CD} 44$ isoforms containing variable regions are expressed only in distinct epithelial cell types (e.g., keratinocytes), activated immune cells, and several types of cancers. ${ }^{9-12}$ Partner molecules of CD44 include hyaluronan, laminin, hepatocyte growth factor, vascular endothelial growth factor, and osteopontin (OPN). ${ }^{9,12}$ Many of them interact with the variant region and are involved in outside-in signaling processes. For example, the interaction between OPN and v7 on macrophages inhibits their production of IL-10. ${ }^{13}$ Furthermore, OPN promotes T-helper type 1 (Th1) responses during chronic intestinal inflammation in mice and is significantly increased in the serum of patients with IBD, suggesting that the CD44-OPN system is deregulated in these patients. ${ }^{14}$

To further clarify the various functions of CD44 in colitis, we have generated mice with targeted deletions of different variant exons without affecting the expression of the large remainder of this complex molecule (Supplementary Figure S1) ${ }^{8}$ This is important because the deletion of total CD44 may induce upregulation of compensatory molecules, such as the receptor for hyaluronan-mediated motility, CD168. ${ }^{15}$ To investigate human IBD-like conditions, we initially used the murine model of T-cell transfer colitis as previously described by Powrie et al. ${ }^{16}$ Here, $C D 4{ }^{+} \mathrm{CD} 45 \mathrm{RB}^{\text {high }}\left(\mathrm{RB}^{\text {hi }}\right)$ cells (naive T cells) are injected into immunodeficient mice, where they encounter antigen-presenting cells (APCs) and are primed by bacterial antigens. After their invasion into the intestinal mucosa, these cells abundantly produce cytokines, which promote chronic intestinal inflammation. The development of this disorder is prevented by cotransfer of $\mathrm{CD} 4{ }^{+} \mathrm{CD} 45 \mathrm{RB}^{\text {low }}\left(\mathrm{RB}^{\text {lo }}\right)$ cells, specified as regulatory $\mathrm{CD} 4^{+} \mathrm{T}$ (induced regulatory $\mathrm{T}$ (iTreg)) cells. ${ }^{17}$ Since the function of APC could be impaired in immunodeficient mice used in this classic T-cell transfer colitis model ${ }^{18}$ we additionally developed and used a new OVA colitis model, using T-cell receptor (TCR) transgenic immunocompetent mice. In both models we found an essential cell-typespecific role of v7-containing CD44 isoforms in colonic inflammation.

\section{RESULTS}

\section{CD44v7 deficiency of recipient mice prevents $R^{\text {hi }}{ }^{\text {T-cell }}$ transfer colitis}

To analyze the role of the CD44 variant exons $v 6$ and $v 7$ in T cell-dependent intestinal inflammation, we first used the classic colitis model described by Powrie et al. ${ }^{16}$ and treated recombination-activating gene 2-deficient $\left(\mathrm{Rag}^{\mathrm{-}^{--}}\right)$mice, which had received $\mathrm{RB}^{\mathrm{hi}} \mathrm{T}$ cells, with blocking antibodies against the products of these two exons. As expected, half of the controls that had not received any antibody developed colitis and died within 6 weeks or had to be killed because of weight loss exceeding $30 \%$ of the initial body weight (Figure 1a). Also, most of the mice, which received anti-v6 treatment, did not survive for 6 weeks or had to be killed due to weight loss. However, the proportion of deaths among anti-v7 antibodytreated mice was only $10 \%$, and remaining surviving mice kept their initial body weight. The outcome of anti-v7 antibody treatment was similar to that obtained with mice receiving Treg cells $\left(\mathrm{RB}^{\mathrm{lo}}\right)$ in addition to $\mathrm{RB}^{\mathrm{hi}}$ cells (Figure 1a).

Since v7-containing CD44 isoforms are expressed on both lymphocytes and APC, in particular after activation, we asked which of these cell populations is decisive for disease. The very close positions of the Rag and Cd44 genes ( $1 \mathrm{cM}$ distance) complicated the generation of doubly targeted mice; however, we finally succeeded in generating mice deficient for both Rag2 and $v 7\left(\operatorname{Rag}^{-1-} \mathrm{Cd} 44 v 7^{-1-}\right)$ and used them as well as Rag $2^{-1-}$ mice as recipients of $\mathrm{RB}^{\text {hi }}$ cells from either wild-type $\left(C d 44^{W T}\right)$ or $C d 44 v 7^{-/-}$mice. Surprisingly, irrespective of the origin of the T cells, Rag2 ${ }^{-1-}$ recipients developed severe disease while $\mathrm{Rag} 2^{-/-} \mathrm{Cd} 44 v 7^{-/-}$remained healthy (Figure 1b). These data suggested a crucial role of $v 7$ productcontaining $\mathrm{CD} 44$ isoforms on APC in intestinal inflammation, while the absence of $\mathrm{v} 7$ on $\mathrm{T}$ cells does not seem to have any impact in this context.

We next investigated whether additional $v 6$ deficiency would modulate the protective effect of $\mathrm{v} 7$ absence. Moreover, we studied the impact of deficiency of another $C d 44$ variant exon, $v 10$, whose product is present in virtually all CD44 isoforms containing variable regions. Therefore, we additionally generated Rag2 ${ }^{-/-} \mathrm{Cd} 44 v 6 / v 7^{-/-}$and $\mathrm{Rag} 2^{-/-} v 10^{-/-}$mice and transferred $C d 44^{W T} \mathrm{RB}^{\text {hi }}$ cells into those animals. Remarkably, Rag2 $2^{-/-} C_{d 44 v 10^{-/-}}$mice, similar to Rag2 $2^{-/-}$ $C d 44^{W T}$ animals, became seriously ill and showed significant weight loss (Figure 1c). Protection of Rag2 ${ }^{-/-} \mathrm{Cd} 44 v 6 / v 7^{-/-}$ mice was similar to that of $R a g 2^{-/-} C d 44 v 7^{-/-}$mice, with a body weight loss of only about $10 \%$ at 8 weeks after $\mathrm{RB}^{\text {hi }}$ cell transfer. Consequently, Rag2 $2^{-/-} \mathrm{Cd} 44^{W T}$ and $\mathrm{Rag}^{-/-}$ $C d 44 v 10^{-1-}$ transfer recipients had considerably shortened colons with a mean length of 9.5 and $8.8 \mathrm{~cm}$, respectively, whereas Rag2 $2^{-1-} \mathrm{Cd} 44 v v 7^{-1-}$ and $\mathrm{Rag} 2^{-/-} \mathrm{Cd} 44 \mathrm{v} 6 / v 7^{-/-}$ mice showed normal lengths with means of around $12 \mathrm{~cm}$ (Figure 1d). Furthermore, histological examination of $\mathrm{Rag2}^{-1-} \mathrm{Cd} 44 v 7^{-1-}$ and Rag2 ${ }^{-1-} \mathrm{Cd} 44 v 6 / v 7^{-1-}$ transfer recipients showed a normal colonic architecture and a minor inflammation score in comparison with Rag2 ${ }^{-/}{ }^{-} \mathrm{Cd} 44^{W T}$ and $R a g 2^{-/-} C d 44 v 10^{-/-}$animals (Figure 1e,f). In summary, specific absence of $\mathrm{v}$, but not general shortening of variable regions, protects recipient mice from $\mathrm{RB}^{\text {hi }}$ transfer colitis. Moreover, an additional absence of its upstream variable exon did not alter the protective effect of v7 deficiency.

\section{Low expression of IFN- $\gamma$ characterizes the colon of Cd44v7 ${ }^{-/-}$transfer recipients}

We next addressed the mechanisms underlying the protection of Rag2 $2^{-1-} \mathrm{Cd} 44 v 7^{-/-}$mice from T-cell-dependent colitis. The pathogenetic cascade in the $\mathrm{RB}^{\text {hi }}$ transfer colitis clearly includes the T-cell effector cytokine IFN- $\gamma \cdot{ }^{16,19}$ However, a harmful role of other T-cell effectors including IL-17A, IL-17F, and IL-22 in gastrointestinal inflammation was additionally postulated. ${ }^{20,21}$ Therefore, we characterized the expression of these T-cell effector cytokines in the colon of the four generated genotypes. The transfer of $\mathrm{RB}^{\text {hi }}$ cells caused increased 

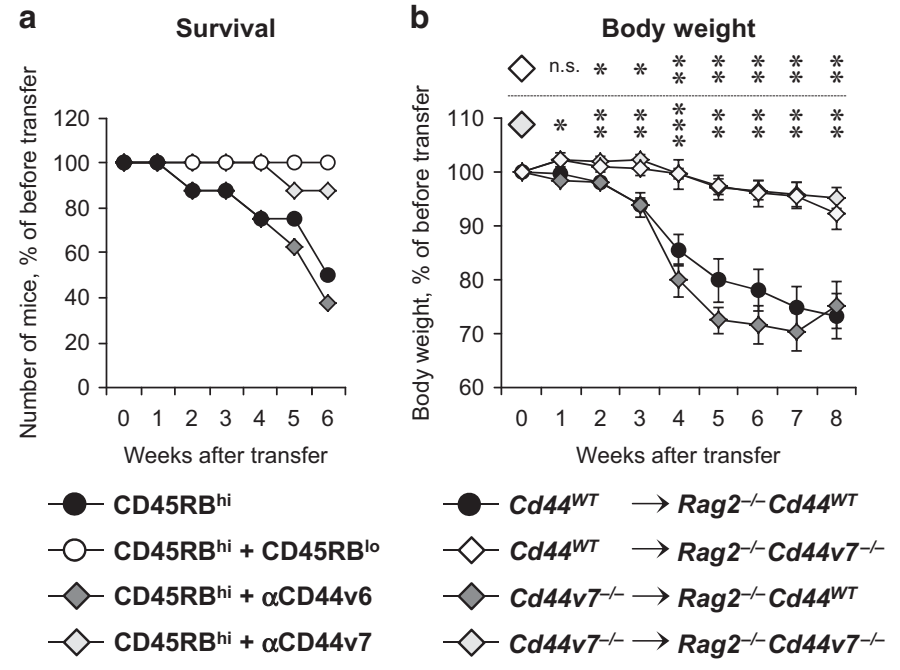

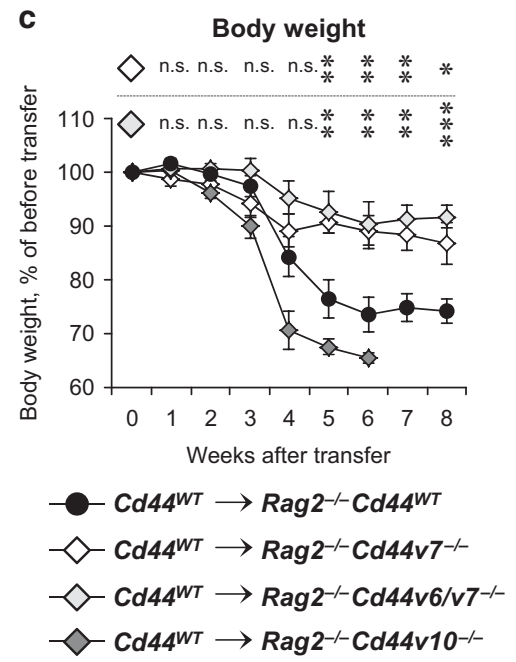

d

Colon length

e Local severity

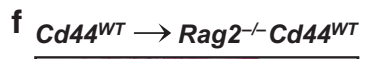

$\mathrm{Cd} 44^{W T} \rightarrow$ Rag2 $^{-/-} \mathrm{Cd} 44 \mathrm{v} 10^{-/-}$
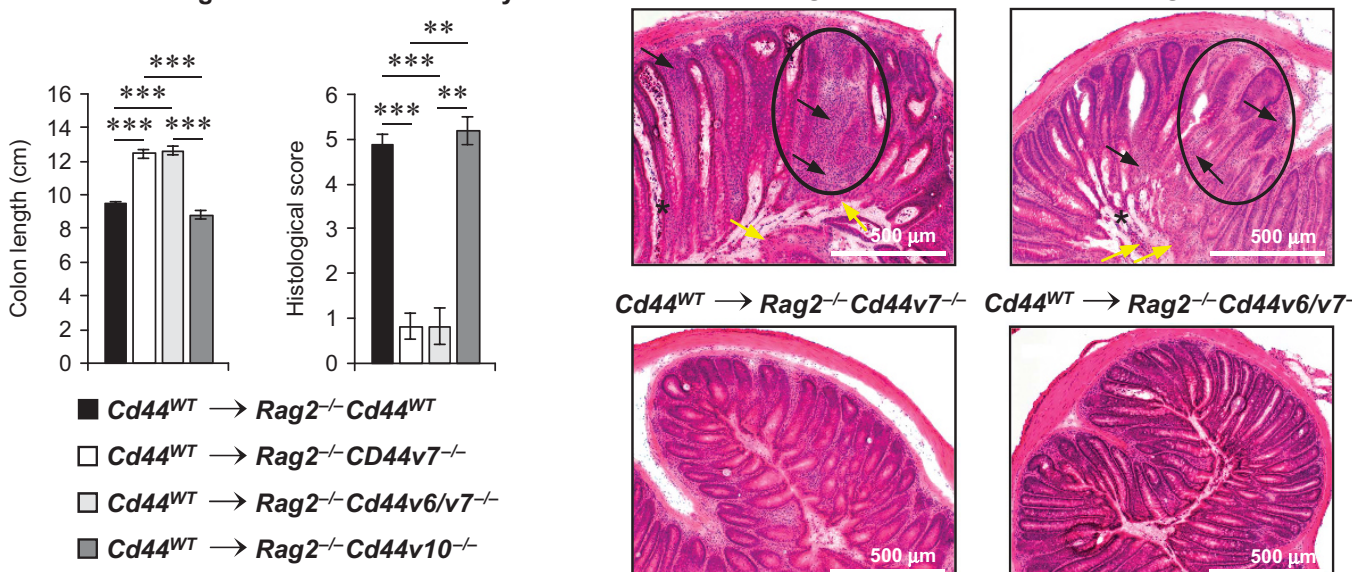

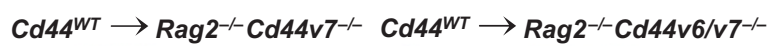
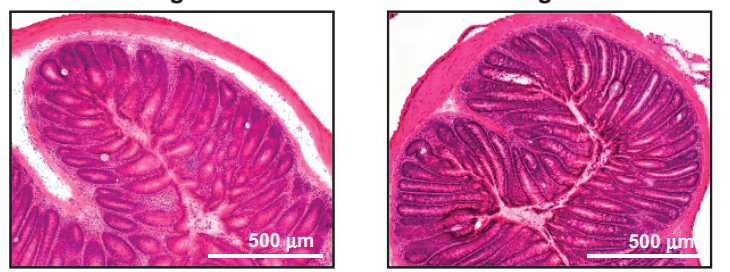

Figure $1 \mathrm{CD} 44 \mathrm{v} 7$ deficiency of recipients prevents murine $\mathrm{CD} 4^{+} \mathrm{RB}^{\mathrm{hi}}$ transfer colitis. (a) Rag2 ${ }^{-/-}$mice (8/group) were injected intraperitoneally (i.p.) with $4 \times 10^{5} \mathrm{RB}^{\mathrm{hi}}$ cells, $4 \times 10^{5} \mathrm{RB}^{\mathrm{hi}}+2 \times 10^{5} \mathrm{RB}^{\text {lo }}$ cells, $4 \times 10^{5} \mathrm{RB}^{\mathrm{hi}}$ cells $+200 \mu \mathrm{g}$ per mouse LN6.1 (anti-CD $44 \mathrm{v} 6 \mathrm{mAb}$ ). or $4 \times 10^{5} \mathrm{RB}^{\mathrm{hi}}$ cells + $200 \mu \mathrm{g}$ per mouse LN7.2 (anti-CD44v7 mAb). The number of surviving mice is given as the \% of starting values. (b) RB ${ }^{\text {hi }}$ cells of $C d 44^{W T}$ or $C d 44 v 7^{-/-}$

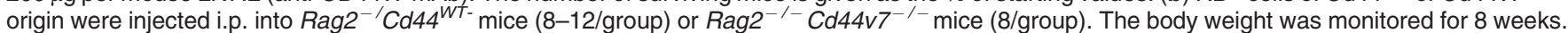
Data are given as percent of starting values (mean \pm s.e.m.). (c) A total of $4 \times 10^{5} \mathrm{RB}^{\text {hi }}$ cells of $C D 44^{W T}$ origin were injected into Rag2 $2^{-/-} C d 44^{W T}$

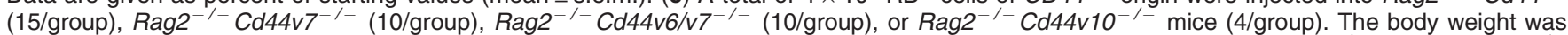

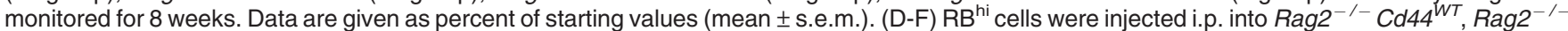

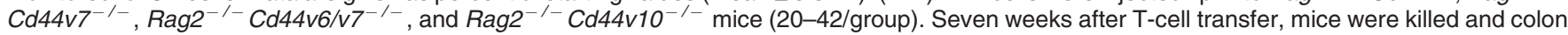
lengths were determined (d) (mean \pm s.e.m.) and hematoxylin and eosin (H\&E) staining of frozen colon sections was performed (f) (one representative section out of 7-9 mice per genotype; bar indicates $500 \mu \mathrm{m}$; black circle: example of an area of inflammation with loss of regular crypt structure; black arrow: immune cell infiltrates; yellow arrow: disrupted brush border; black asterisk: elongation of crypt). Histological scores ranging from 0 (no changes) to 6 (extensive cell infiltration and tissue damage) were determined (e). Data from 7-9 mice per group are shown as mean \pm s.e.m.). Results of one out of four to seven independent experiments are shown in (a-d). Statistical significance of deviations is shown between control group (black filled circle) vs. white/light gray-filled square groups only, as indicated. ${ }^{*} P \leq 0.05 ;{ }^{* \star} P \leq 0.01 ;{ }^{* * \star} P \leq 0.001$ (Mann-Whitney U-test, two-tailed). NS, not significant.

expression of IFN- $\gamma$, IL-17A, IL-17F, and IL-22 in Rag2 $2^{-/-}$ recipients compared with immunocompetent $R a g 2^{+/+}$mice without transfer (Figure 2a). However, the increase of all these cytokines was significantly less pronounced in the Rag $2^{-1-}$ $\mathrm{Cd} 44 v 7^{-1-}$ and $\mathrm{Rag} 2^{-1-} \mathrm{Cd} 44 \mathrm{v} 6 / \mathrm{v} 7^{-/-}$transfer recipients. Unexpectedly, the expression profile of the strongly inflamed colons of Rag2 $2^{-/-} \mathrm{Cd} 44 \mathrm{v} 10^{-/-}$transfer recipients did not completely follow the $R a g 2^{-/-} C d 44^{W T}$ pattern. In fact, although high IFN- $\gamma$ levels were found in both genotypes and clearly associated with intestinal pathology, levels of IL-17A, IL-17F, and IL-22 were actually reduced in Rag2 $2^{-/-}$

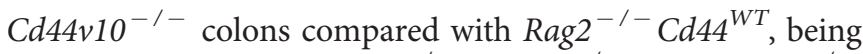
similar to those in $\mathrm{Rag}^{-/-} \mathrm{Cd} 44 v 7^{-/-}$and $\mathrm{Rag} 2^{-1-}$ $C d 44 v 6 / v 7^{-1-}$ mice. Expression levels of molecules known to be regulated by IL-17 and IL-22, including the antibacterially acting S100A9 and sialomucin 1 (Muc1) (2,23 $^{223}$ reflected the IL-17A/F and IL-22 expression profile (Figure 2b), and thereby confirmed the relatively reduced biological activity of these cytokines in $\mathrm{Rag} 2^{-/-} \mathrm{Cd} 44 \mathrm{v} 10^{-/-}$mice. Our observations indicate that, in contrast to IFN $-\gamma$, the cytokines IL-17A, IL-17F, and IL-22 were not functionally involved in the development of intestinal pathology in the $\mathrm{RB}^{\text {hi }}$ transfer model. 
a

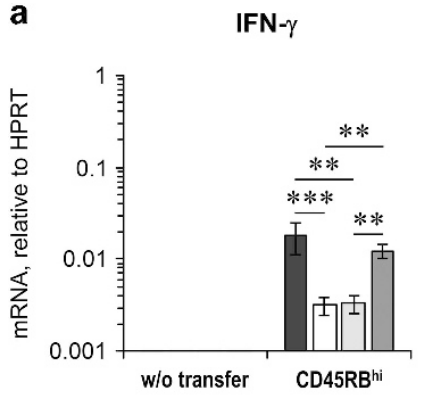

IL-17A

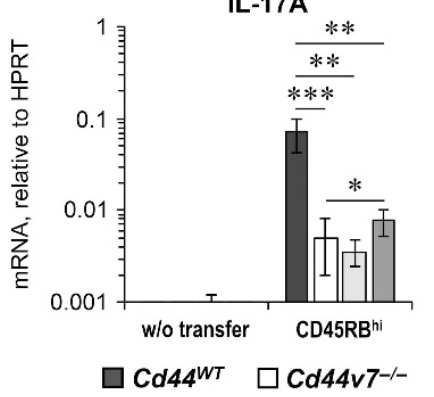

b

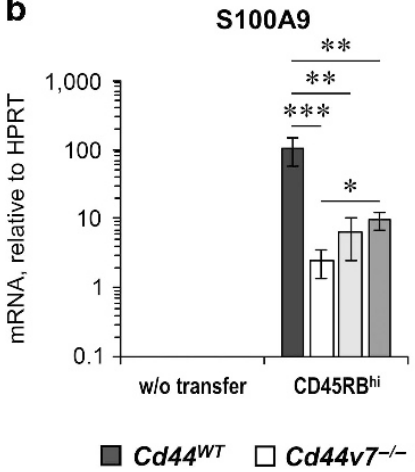

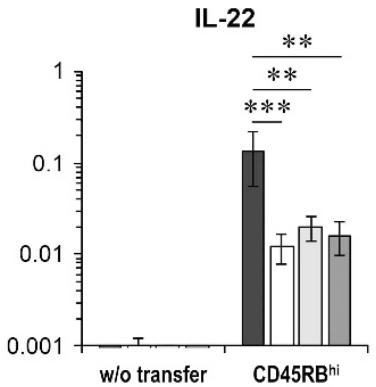

IL-17F

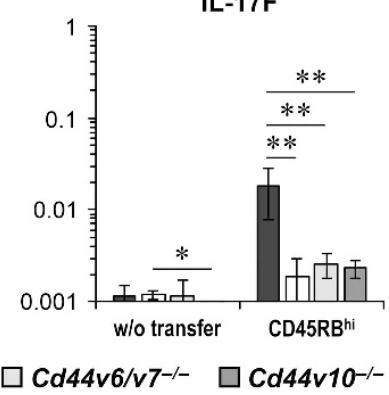

Muc1

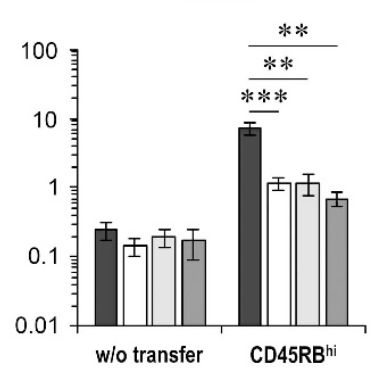

Figure 2 Low colonic interferon- $\gamma($ IFN- $\gamma$ ) expression is a key feature of healthy $\operatorname{Rag}^{-/-} \mathrm{Cd} 44 \mathrm{~V} 7^{-/-}$transfer recipients. (a and b) $R a g 2^{-I^{-}}$

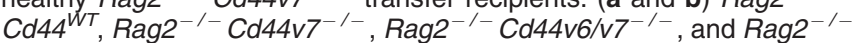
$C d 44 v_{10} 0^{-1-}$ mice were injected intraperitoneally (i.p.) with $4 \times 10^{5} \mathrm{RB}^{\mathrm{hi}}$ cells of $C d 44^{W T}$ origin and killed 7 weeks after T-cell transfer. Untreated immunocompetent $\left(\operatorname{Rag}^{+/+}\right) \mathrm{Cd} 44^{W T}, \mathrm{Cd} 44 \mathrm{v} 7^{-/-}, \mathrm{Cd} 44 \mathrm{v} 6 / \mathrm{v} 7^{-/-}$, and $C d 44 v_{10}^{-/-}$mice were used as controls. Colon gene expression was analyzed by quantitative PCR (qPCR). Data from five to seven mice per genotype (mean \pm s.e.m.) are given as relative to hypoxanthine phosphoribosyltransferase (HPRT) expression. ${ }^{*} P \leq 0.05$; ${ }^{\star *} P \leq 0.01$; ${ }^{\star \star \star} P \leq 0.001$ (Mann-Whitney $U$-test, two-tailed).

\section{Absence of colitis in $\mathrm{Cd44v7^{-/- }}$ transfer recipients is not based on local absence of Th1 cells}

Next, we investigated potential causes for the different expression of the T-cell effector cytokines in the colon of the four genotypes after $\mathrm{RB}^{\text {hi }}$ transfer, considering different possibilities. At this, we initially found that colonic $\mathrm{CD} 4{ }^{+}$ T-cell counts were similar in all groups of recipients (Figure 3a,b). We then asked for the functional composition of Th cells and quantified the expression of transcription factors associated with individual effector Th-cell subsets. Surprisingly, the expression levels of T-bet, ROR $\gamma \mathrm{t}$, and GATA3 were not reduced in the colon of $\mathrm{Rag}^{-/-}$ $C d 44 v 7^{-1-}$ transfer recipients compared with $R a g 2^{-/-}$ $C d 44^{W T}$ recipients but even significantly increased in the

case of T-bet and ROR $\gamma \mathrm{t}$ (Figure 3c). The abundance of T-bet argued against a reduced Th1-cell presence as the mechanism underlying the low colonic IFN- $\gamma$ production in $C d 44 v 7^{-/-}$ transfer recipients, and instead suggested an impaired activity of Th1 cells.

\section{Colons of $\mathrm{Cd} 44 \mathrm{v7^{-/- }}$ transfer recipients contain high numbers of Treg cells and low levels of Th1- and Th17- activating cytokines}

The elevated ROR $\gamma \mathrm{t}$ levels in colons of $\mathrm{Rag} 2^{-/-} \mathrm{Cd} 44 v 7^{-/-}$ transfer recipients prompted us to investigate the actual expression of transcription factors among T-cell populations. For that purpose, Th1, Th2, Th17, and iTreg cells were generated from murine naive $\mathrm{CD}^{+}{ }^{+} \mathrm{T}$ cells by activation via TCR and CD28 under Th cell-specific polarizing conditions (Supplementary Table S1). As demonstrated in Figure 4a, not only Th17 cells but also iTreg cells expressed substantial ROR $\gamma \mathrm{t}$ levels, whereby iTreg cells additionally and nearly exclusively expressed Foxp3 (Figure 4a). Furthermore, investigating the generation of iTreg cells in the presence of LE540, a chemical antagonist of retinoic acid receptor (RAR), we confirmed the importance of retinoic acid (RA) for the development of iTreg (Figure $4 \mathbf{b}$ ). When analyzing the number of Foxp $3^{+} \mathrm{T}$ cells in the colons of all four mouse genotypes after transfer, significantly higher numbers of Treg cells $(\sim 10$-fold increase) were detected in $\operatorname{Rag} 2^{-/-} \mathrm{Cd} 44 v 7^{-/-}$and Rag2 ${ }^{-/-} C d 44 v 6 / v 7^{-/-}$mice compared with $\mathrm{Rag}^{-/-}$ $C d 44^{W T}$ and $R a g 2^{-/-} C d 44 v 10^{-/-}$mice (Figure $4 \mathbf{c}, \mathbf{d}$ ).

We next investigated the cause of the high iTreg-cell numbers in $R a g 2^{-/-} C d 44 v 7^{-/-}$transfer animals. The development of these cells is dependent on the presence of TGF- $\beta$ in the simultaneous absence of interleukin-6 (IL-6). In fact, TGF- $\beta$ upregulates ROR $\gamma$ t expression, ${ }^{24}$ and-together with its cofactor RA-also induces Foxp3 expression and the suppressive activity of Treg cells. ${ }^{25}$ In contrast, IL-6 and IL-27, via signal transducer and activator of transcription 3 (STAT3), counteract Foxp 3 expression. ${ }^{26}$ In line with the IL- 6 absence as prerequisite for the elevated presence of iTreg cells, we found significantly lower levels of IL- 6 in the colon of Rag2 $2^{-1-}$ $C d 44 v 7^{-1-}$ and $R a g 2^{-/-} C d 44 v 6 / v 7^{-/-}$transfer recipients as compared with Rag2 ${ }^{-/-} \mathrm{Cd} 44^{W T}$ and $\mathrm{Rag} 2^{-/-} \mathrm{Cd} 44 \mathrm{v} 10^{-/-}$ mice (Figure 5a). Moreover, only marginal levels of IL-27 were detected in $\mathrm{Rag} 2^{-/-} \mathrm{Cd} d 4 v 7^{-/-}$and $\mathrm{Rag} 2^{-/-} \mathrm{Cd} 44 v 6 / v 7^{-/-}$ transfer recipients (Figure 5a). According to the reduced presence of STAT3-activating IL-6 and IL-27, we found considerable lower numbers of phospho-STAT3-containing lymphocytes in the colonic infiltrates from $\mathrm{Rag}^{-1-} \mathrm{Cd} 44 \mathrm{v} 7^{-1-}$ and $\operatorname{Rag} 2^{-1-} C d 44 v 6 / v 7^{-1-}$ mice in comparison with those from Rag2 ${ }^{-/-} C d 44^{W T}$ and $R a g 2^{-/-} C d 44 v 10^{-/-}$mice (Figure 5b,c). In fact, in the diseased $R a g 2^{-/-} C d 44^{W T}$ and Rag2 $^{-/-}$Cd44v10 $0^{-/-}$mice, phospho-STAT3-positive cells were mainly localized within the colonic infiltrates inside the destroyed crypts (Figure 5b), whereas in the healthy Rag2 ${ }^{-1-} \mathrm{Cd} 44 v 7^{-/-}$and $\operatorname{Rag} 2^{-/-} \mathrm{Cd} 44 v 6 / v 7^{-/-}$transfer recipients, phospho-STAT3-positive cells were mainly confined to the lining of crypts. It is worth mentioning that 
a

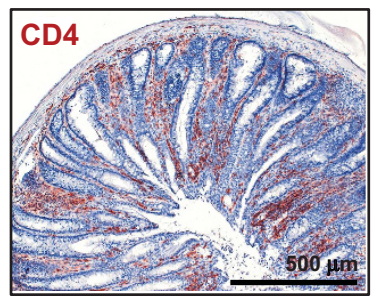

b
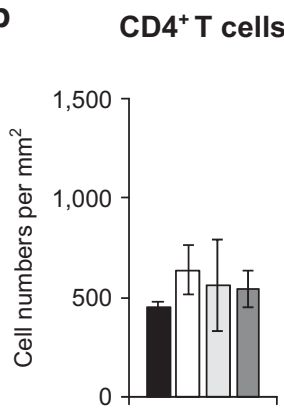

Cd44v7 ${ }^{-/-}$

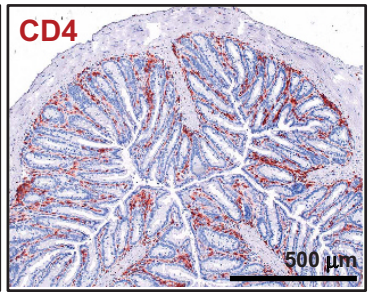

C

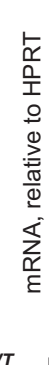

$C d 44 v 6 / v 7^{-/-}$

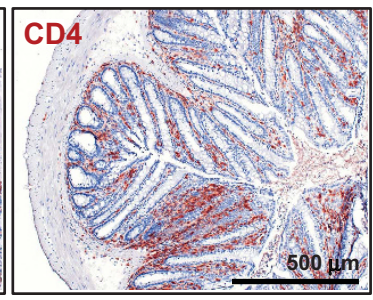

T-bet

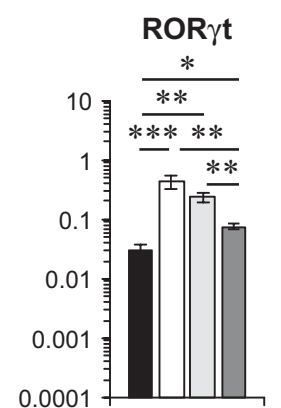

$0.0001+$
Cd44v10"--

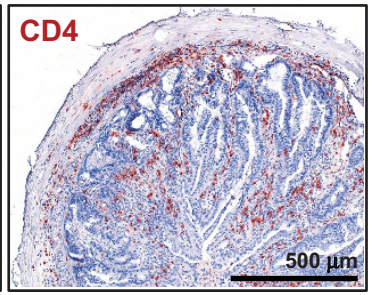

GATA3

$C d 44^{W T}$

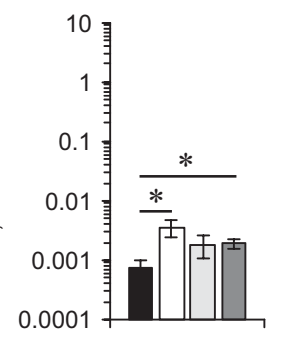

$\mathrm{Cd} 44 \mathrm{v7}^{-/-}$

Cd44v6/v7 $7^{-/-}$

$\square \mathrm{Cd} 44 \mathrm{v} 10^{-/-}$

Figure 3 Low colonic interferon- $\gamma$ (IFN- $\gamma$ ) presence in healthy Rag $2^{-/-} \mathrm{Cd} 44 \mathrm{~V} 7^{-/-}$transfer recipients may not be assigned to reduced presence of

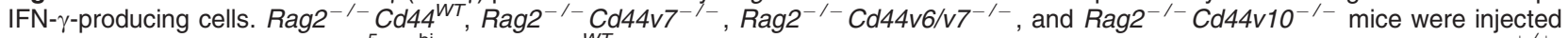
intraperitoneally (i.p.) with $4 \times 10^{5} \mathrm{RB}^{\text {hi }}$ cells of $C d 44^{W T}$ origin and killed 7 weeks after T-cell transfer. Untreated immunocompetent $\left(R a g 2^{+/+}\right) C d 44^{W T}$, $C d 44 v 7^{-1-}, C d 44 v 6 / v 7^{-1-}$, and $C d 44 v 10^{-1-}$ mice were used as controls. (a and b) Detection of CD4 ${ }^{+}$cells in frozen colon sections was performed by immunohistochemistry. One representative section out of five independent stainings/genotype is shown (a) $(\mathrm{Bar}=500 \mu \mathrm{m})$. CD4 ${ }^{+}$cell counts from two to four mice per genotype are given as mean \pm s.e.m. (b). (c) Colon gene expression was analyzed by quantitative PCR (qPCR). Data from five to seven mice per genotype (mean \pm s.e.m.) are given as relative to hypoxanthine phosphoribosyltransferase (HPRT) expression. ${ }^{\star} P \leq 0.05 ;{ }^{* \star} P \leq 0.01$;

${ }^{* * *} P \leq 0.001$ (Mann-Whitney U-test, two-tailed).

the v7 ligand OPN was locally expressed even in colons of mice without transfer, and its levels were upregulated upon induction of $\mathrm{RB}^{\text {hi }}$ transfer colitis (Figure $\mathbf{5 d}$ and Supplementary Figure S2). OPN levels positively correlated with the expression of IL-6, but not with T-cell derived cytokines such as IL-17F (Figure 5e).

Since iTreg are not only able to directly inhibit the activation of $\mathrm{T}$ cells but also to counteract the cytokine production by APCs, we next analyzed the colonic expression of APC cytokines known to induce T-cell effector cytokines, namely IL-12, IL-1 $\beta$, and IL-23, in the colons of all four genotypes of mice after

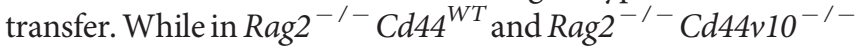
mice the colonic expression of IL-12p35 and IL- $1 \beta$ was increased compared with immunocompetent $\mathrm{Rag} 2^{+/+}$control mice, this increase was suppressed in $\mathrm{Rag2} 2^{-1-} \mathrm{Cd} 44 v 7^{-/-}$and Rag2 ${ }^{-1-}$ $C d 44 v 6 / v 7^{-1-}$ mice (Figure 5f). In summary, our data suggest the following cascade underlying the protection from colitis in $C d 44 v 7^{-1-}$ transfer recipients: a deficient local production of STAT3-activating IL-6 and IL-27 leads to an increased colonic presence of iTreg cells that both directly and via inhibition of the APC's production of IL-12 and IL-1 $\beta$ causes locally reduced production of Th1 effector cytokines.

\section{CD44v7 on macrophages is essential for OVA antigen- specific colitis}

To exclude confounding effects due to the immunodeficiency in Rag2 ${ }^{-/-} \mathrm{Cd} 44 v 7^{-/-}$mice, we confirmed and mechanistically extended our findings in a newly, self-developed model of T-cell-dependent intestinal inflammation, namely OVA antigen-specific colitis. For this purpose, Th1 cells from OVAspecific TCR-transgenic mice (DO11.10, designated as OVA$\mathrm{TCR}^{\mathrm{tg}}$ ) with and without $C d 44 v 7$ deletion were transferred into immunocompetent $C d 44^{W T}$ and $C d 44 v 7^{-1-}$ recipients. T-cell activation was induced by subsequent intrarectal OVA application. Bovine serum albumin (BSA) challenge served as a control. As a prerequisite for further analyses, we firstly ensured that OVA-fluorescein isothiocyanate (FITC) was taken up by mucosal APC (especially by macrophages) and that this uptake was independent of the presence or absence of CD44v7 expression (Figure 6a) and that OVA-TCR ${ }^{\mathrm{tg}} \mathrm{Cd} 44^{W T} \mathrm{Th} 1$ cells induced strong colitis in $C d 44^{W T}$ transfer recipients (Figure 6b). Furthermore, we showed that despite intraperitoneal application of the transfer $\mathrm{T}$ cells, antigen-specific T-cell proliferation seemed to be preferentially restricted to the lamina propria in the gut of $C d 44^{W T}$ transfer recipients as it did not occur in the mesenteric lymph nodes (Figure 6c). This demonstrates that the OVA antigen-specific colitis is an appropriate model for moderate IBD, which is devoid of severe systemic involvement.

In concordance with our data from the $\mathrm{RB}^{\text {hi }} \mathrm{T}$-cell transfer colitis model, we found that both OVA-TCR ${ }^{\mathrm{tg}} \mathrm{Cd} 44^{W T}$ and OVA-TCR ${ }^{\operatorname{tg}} C d 44 v 7^{-1-} \mathrm{T}$ cells efficiently induced colitis in $C d 44^{W T}$ mice, but not in $C d 44 v 7^{-1-}$ recipients (Figure 6b,df). Assuming that $\mathrm{CD} 44 \mathrm{v} 7$ isoform expression on macrophages 

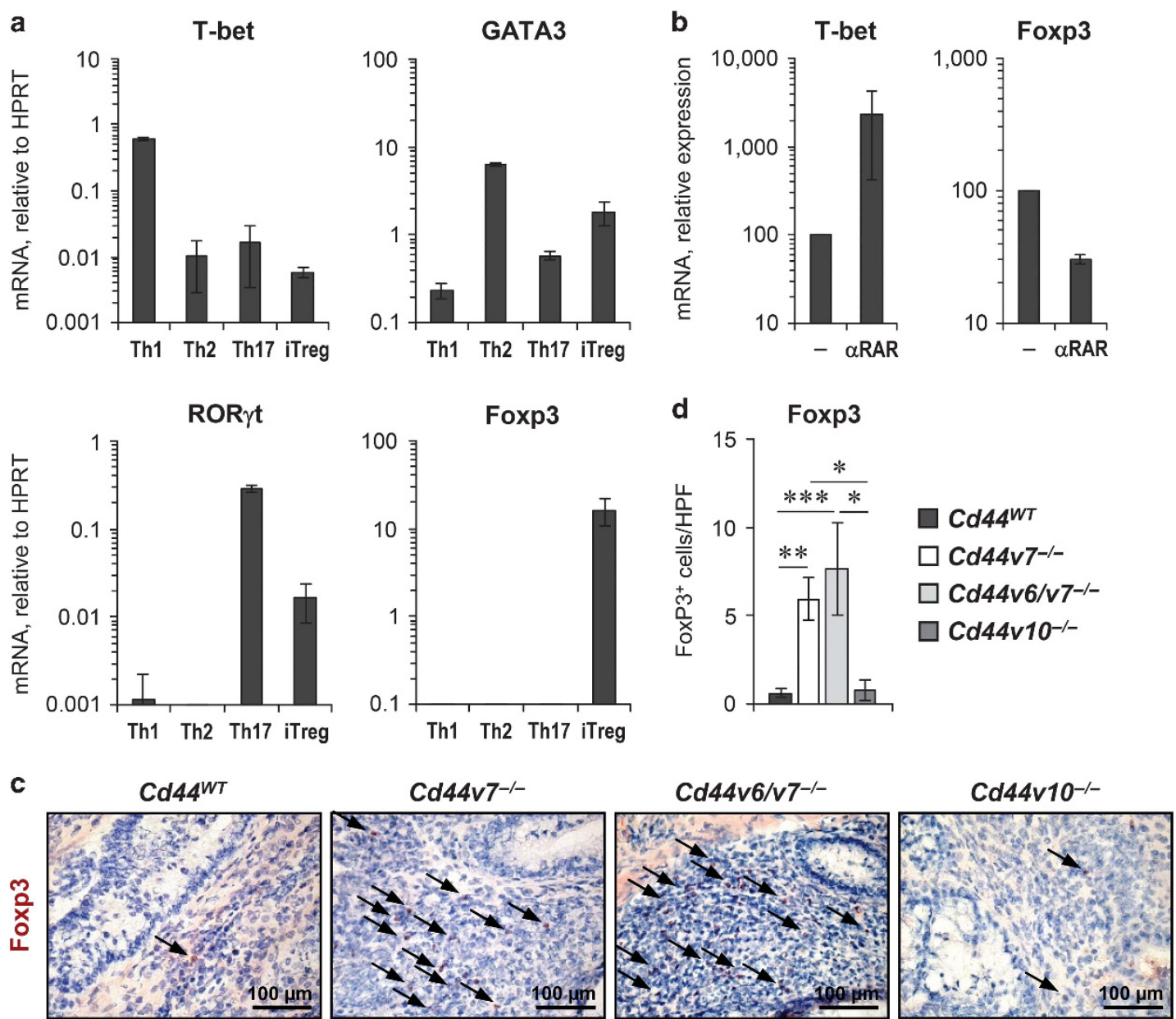

Figure 4 The colon of healthy Rag2 ${ }^{-/-} \mathrm{Cd} 44 \mathrm{~V} 7^{-1-}$ transfer recipients harbors large numbers of induced regulatory $\mathrm{T}$ (iTreg) cells. (a and $\left.\mathbf{b}\right)$ Murine CD25 ${ }^{-}$CD4 ${ }^{+} \mathrm{CD}_{22} \mathrm{~L}^{\text {high }}$ cells, isolated from spleen and lymph nodes of C57BL/6 mice, were stimulated via CD3 and CD28 in the presence of T-helper (Th) subset-polarizing conditions for 4 days, followed by quantitative PCR (qPCR)-based gene expression analysis. (b) Murine iTregs were differentiated in the absence or presence of a pan-retinoic acid receptor (RAR) antagonist as indicated, followed by qPCR-based gene expression analysis. Data are given as relative to hypoxanthine phosphoribosyltransferase (HPRT) expression (mean \pm range) from two independent experiments. (c and d) Rag $2^{-}$

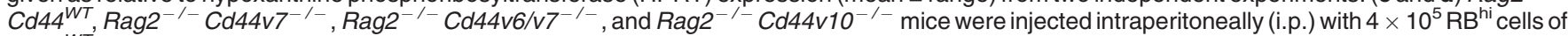
$C d 44^{W T}$ origin and killed 7 weeks after T-cell transfer. Immunohistochemical detection of Foxp3 in frozen colon sections was performed. (c) One representative section out of five mice per genotype are shown (Bar $=100 \mu \mathrm{m}$; black arrows indicate Foxp3 ${ }^{+}$cells). (d) Quantification of Foxp3 ${ }^{+}$cells was carried out in 15-36 high power fields (HPF) out of four to seven mice per genotype (mean \pm s.e.m.). ${ }^{*} P \leq 0.05 ;{ }^{* *} P \leq 0.01 ;{ }^{* * \star} P \leq 0.001$ (MannWhitney U-test, two-tailed).

is decisive for intestinal inflammation, we then transferred the OVA-specific Th1 cells together with a small number of macrophages of $C d 44^{W T}$ origin ( $2 \%$ of total) into $C d 44 v 7^{-1-}$ recipients. As demonstrated in Figure 6e,f, this macrophage addition was sufficient to induce severe colitis in the $C d 44 v 7^{-1-}$ recipients, with histology similar to that observed in the $C d 44^{W T}$ recipients (Figure 6f).

\section{$C d 44 \mathrm{vT}^{-1-}$ macrophages induce Foxp3 expression in $\mathrm{T}$ cells both in vivo and in vitro}

Based on our hypothesis of the relationship between macrophage CD44v7 expression and iTreg absence as the decisive factor for intestinal inflammation, we analyzed iTreg numbers and inflammation in OVA antigen-specific colitis. Indeed, the proportion of Foxp $3^{+} \mathrm{T}$ cells was approximately five times higher in the lamina propria of OVA-challenged $C d 44 v 7^{-/-}$ transfer recipients than in $C d 44^{W T}$ transfer recipients (Figure 7a). More conclusively, the cotransfer of $C d 44^{W T}$ macrophages significantly prevented this Foxp $3^{+}$T-cell increase of $C d 44 v 7^{-1-}$ recipients (Figure 7a) and led to mucosal inflammation (Figure 6e,f).

Finally, we isolated OVA-specific $\mathrm{T}$ cells from OVA$\mathrm{TCR}^{\mathrm{tg}} C d 44^{W T}$ mice and macrophages from $C d 44^{W T}$ and $C d 44 v 7^{-1-}$ mice. While coculture of OVA-TCR ${ }^{\mathrm{tg}} C d 44^{W T}$ $\mathrm{T}$ cells with $C d 44^{W T}$ macrophages in the presence of OVA did not promote Foxp3 expression, the OVA-TCR ${ }^{\mathrm{tg}} \mathrm{C} d 44^{W T} \mathrm{~T}$ cells cocultured with $C d 44 v 7^{-1-}$ macrophages clearly did (Figure $7 b$ ). These data suggest that CD44v7 expression on macrophages prevents iTreg development and induces T-cell-dependent gut inflammation.

\section{Human monocytic cells strongly express CD44v7}

The last part of our study focused on the translational aspect of our work. First, we quantified the expression of CD44s, total 

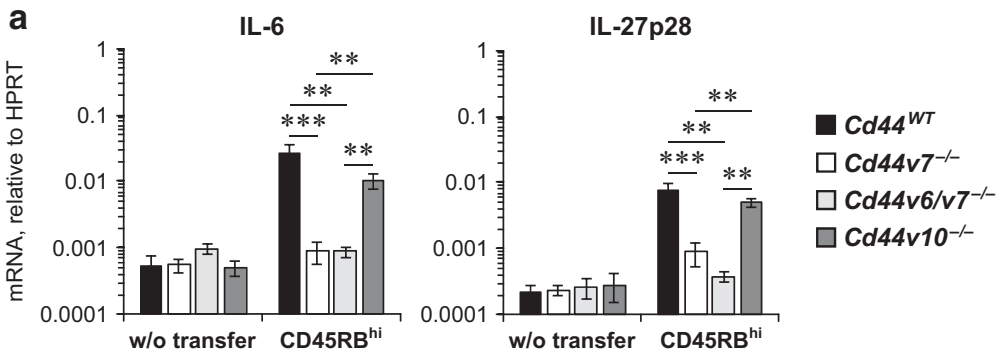

b

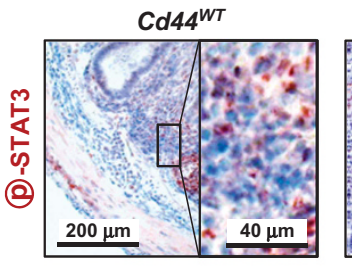

Cd44v10-/

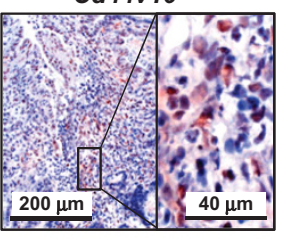

$C d 44 v 7^{-/}$

Cd44v6/v7 $7^{-1-}$
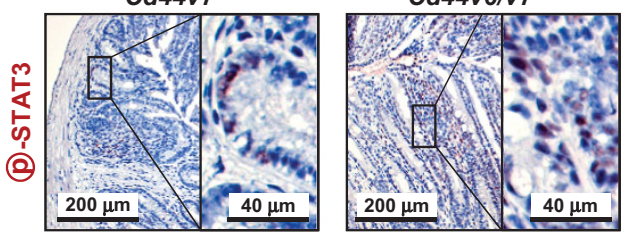

C

(D)-STAT3

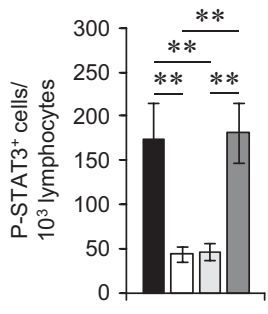

- $\mathrm{Cd} 44^{\mathrm{WT}}$

$\square \mathrm{Cd} 44 v 7^{-/-}$

$\square C d 44 v 6 / v 7^{-/-}$

$\square \mathrm{Cd} 44 \mathrm{v} 10^{-/-}$
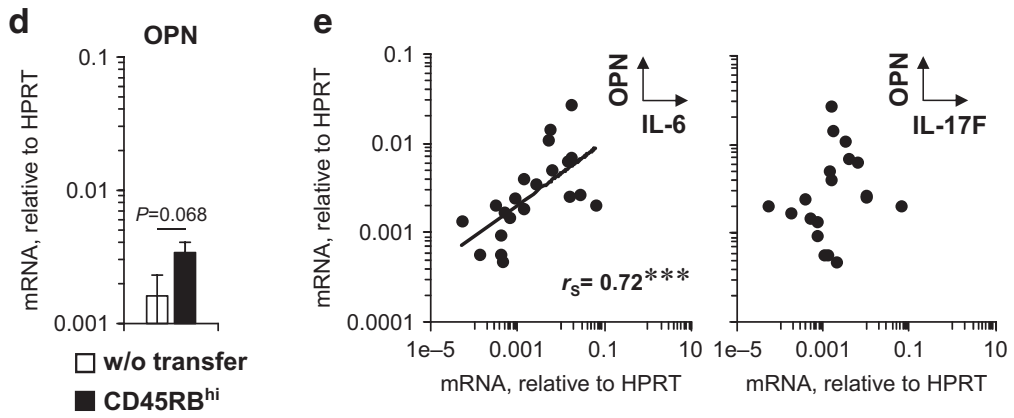

f

IL-12p35
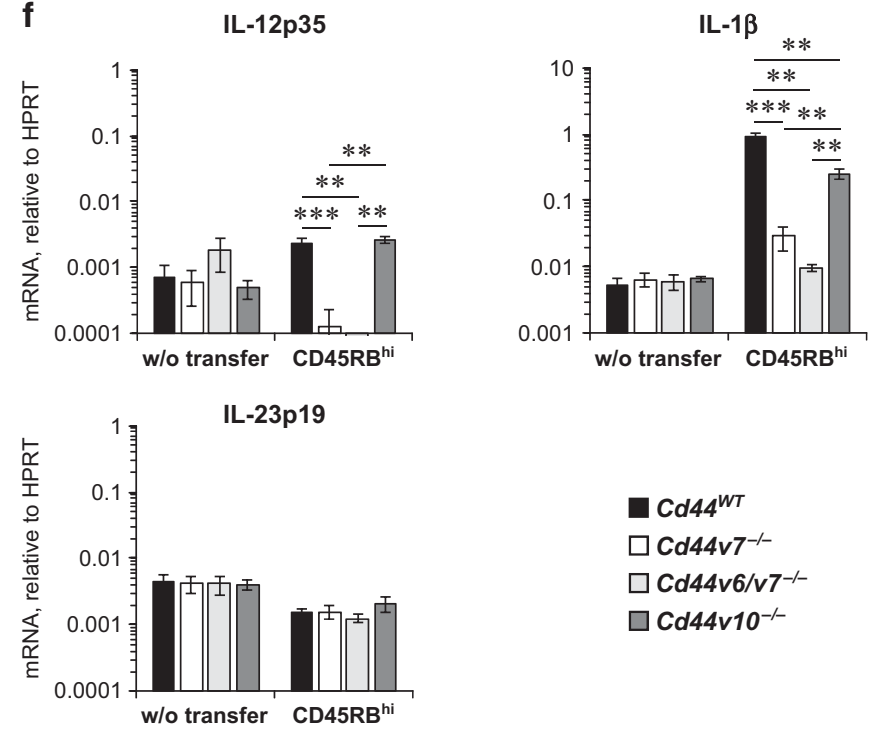

Cd44 ${ }^{W T}$

$\square \mathrm{Cd} 44 \mathrm{~V} 7^{-/-}$

$\square \mathrm{Cd} 44 \mathrm{v} 6 / \mathrm{v} 7^{-/-}$

$\square \mathrm{Cd} 44 \mathrm{v} 10^{-/-}$ 
isoforms containing variant exons $(\mathrm{CD} 44 \mathrm{v})$, and CD44v7 in human-activated monocytic cells and different T-cell subpopulations. As demonstrated in Figure 8a,b clear and comparable expressions of CD44s were detected in all cell types. However, CD44v7 was very strongly expressed by monocytes/macrophages, whereas only moderate and 1,000times lower expression was detected in dendritic cells (DCs) and $\mathrm{T}$ cells, respectively. Then, we generated Th1, Th2, Th17, and iTreg cells from human naive $\mathrm{CD} 4^{+} \mathrm{T}$ cells by activation via TCR and $\mathrm{CD} 28$ under specific polarizing conditions (Supplementary Table S2) and could show that the transcription factor pattern in murine and human T-cell sub-populations was very similar (Figure 8c). In addition to their strong specific Foxp3 expression, human iTreg cells also demonstrated marked ROR $\gamma \mathrm{t}$ expression.

\section{The CD44 ligand OPN promotes IL-6-dominated inflammation and is associated with human IBD}

Since the production of IL-6, via regulating local iTreg cell numbers, seems to be a decisive event in the pathogenetic axis of murine T-cell-dependent intestinal inflammation, we investigated whether there is also a relationship between CD44v7 and cytokines that modulate T-cell subsets in human IBD.

Thus, we analyzed the blood of patients suffering from Crohn's disease and from healthy control individuals. As shown in Figure 9a, there were significantly elevated levels of both OPN and IL- 6 in the blood of Crohn's disease patients compared with healthy donors, whereas IL- $1 \beta$ and IL-12 levels were not increased. The quantification of samples from additional healthy individuals, a further Crohn's disease patient cohort, and psoriasis patients selected as they also show inflammation at an outer body barrier, emphasized again the strong significance level of the differences between Crohn's disease patients and healthy participants regarding OPN and IL-6 blood concentrations (Figure 9b). The reanalysis of these samples using a different enzyme-linked immunosorbent assay (ELISA) system that detects free as well as bound forms of IL-6 protein confirmed this finding (Supplementary Figure S3). Interestingly, the OPN and IL-6 blood levels of psoriasis patients were similar to the concentrations of healthy donors. This demonstrates that levels of these cytokines are not generally elevated upon inflammation but their increase appears to be specific for Crohn's disease. Furthermore, we observed a positive association between the blood levels of OPN and IL-6 in these samples, suggesting a direct relationship between these molecules (Supplementary Figure S4).

Subsequent in vitro experiments using human peripheral blood mononuclear cells (PBMCs) disclosed that OPN at levels observed in the blood of Crohn's disease patients substantially increased IL-6 production (Figure 9c). The absence or minimal induction of IL- 12 and IL-1 $\beta$ by OPN in human immune cells suggested that in mice the decreased levels of these cytokines in healthy $C d 44 v 7^{-1-}$ transfer recipients were not caused by absence of OPN-Cd44v7 interaction but rather by elevated iTreg cells. By comparing the response of different PBMC populations towards OPN stimulation, we revealed that IL-6 production was present in monocyte cultures, whereas it was virtually absent from the OPN-stimulated memory $\mathrm{T}$ cells (Figure 9d). This was in line with the observed high and very low CD44v7 expression in monocytic cells and T-cell subpopulations, respectively (Figure 8a,b).

The relative deficiency of IL-10 in Crohn' disease patients has been suggested to strengthen the inflammation and contribute to chronification of the immune processes. Interestingly, the presence of neutralizing anti-IL-10 antibodies (mimics the relative IL-10 deficiency in Crohn's disease patients) clearly strengthened the OPN-induced IL-6 production (Figure 9e), likely to be due to blockade of membrane-bound IL-10 molecules. ${ }^{27}$ Importantly, OPN-induced IL-6 production by monocytic cells was identified to depend on the interaction of OPN with the product of variant exon v7 of the CD44 molecule. In fact, preincubation of OPN with a recombinant CD44v7 peptide actually reduced OPN-induced IL-6 production from monocytes by nearly $\sim 74 \%$. (Figure 96 ).

Additionally, we investigated the relationship of blood OPN levels with disease duration for Crohn's disease patients. Importantly, these parameters did not correlate (Figure 9g), suggesting that elevated OPN levels in these patients are not the consequence of chronic inflammation. Moreover, in line with the known role of TNF- $\alpha$ as a driver of OPN production, ${ }^{28}$ we observed striking lower blood levels of OPN in patients treated with TNF- $\alpha$-blocking agents compared to those treated with classical antimetabolites (Figure $\mathbf{9 h}$ ), which was paralleled by a trend for better therapy response in the group treated with

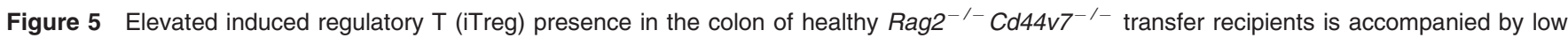
abundance of Foxp3-counteracting cytokines and their signaling events as well as low levels of T-helper type 1 (Th1)- and Th17-activating cytokines.

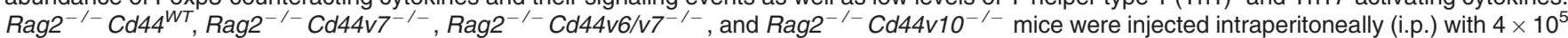
$\mathrm{RB}^{\text {hi }}$ cells of $C D 44^{W T}$ origin and killed 7 weeks after T-cell transfer. (a) Colon gene expression was analyzed by quantitative PCR (qPCR). Untreated immunocompetent $\left(\operatorname{Rag}^{+/+}\right) \mathrm{Cd} 44^{W T}, \mathrm{Cd} 44 v 7^{-1-}, C d 44 v 6 / v 7^{-/-}$, and $C d 44 v 10^{-}{ }^{-}$mice were used as controls. Data from five to seven mice per genotype (mean \pm s.e.m.) are given as relative to hypoxanthine phosphoribosyltransferase (HPRT) expression. (b and c) Immunohistochemical detection of phosphorylated signal transducer and activator of transcription 3 (STAT3) in frozen colon sections was performed (one representative section out of seven mice per genotype is shown; bar $=200 \mu \mathrm{m}$; higher magnification inserts: bar $=40 \mu \mathrm{m}$ ). (c) Positive cells from (b) were counted per 1,000 lymphocytes. Data from six to seven mice per genotype are given as mean \pm s.e.m. (d-f) Colon gene expression was analyzed by qPCR. (d) OPN

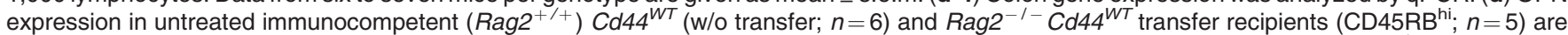
given as relative to HPRT expression (mean \pm s.e.m.). (e) Individual OPN expressions in colon of untreated immunocompetent $\left(R a g 2^{+/+}\right) C d 44^{W t}$ and

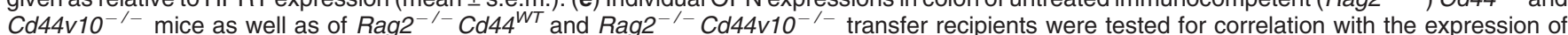
cytokines by Spearman's rank correlation analysis (two-tailed, $\left.{ }^{\star * \star} P \leq 0.001\right)$. (f) Untreated immunocompetent $\left(\operatorname{Rag}^{+/+}\right) \mathrm{Cd} 44^{W T}, C d 44 v 7^{-}{ }_{-}, C d 44 v 6 /$ $v 7^{-1-}$, and $C d 44 v 10^{-1-}$ mice were used as controls. Data from five to seven mice per genotype (mean \pm s.e.m.) are given as relative to HPRT expression. ${ }^{* \star} P \leq 0.01 ;{ }^{* * *} P \leq 0.001$ (Mann-Whitney U-test, two-tailed). 
a

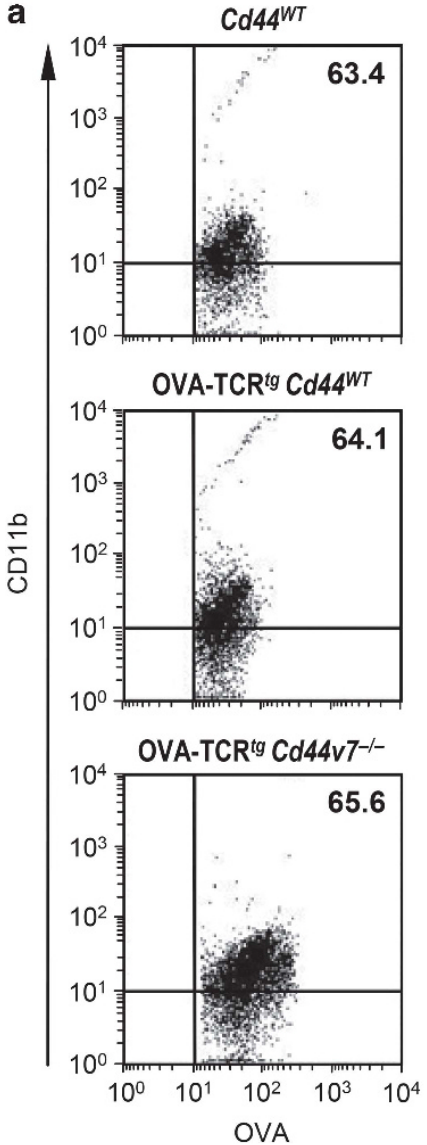

e

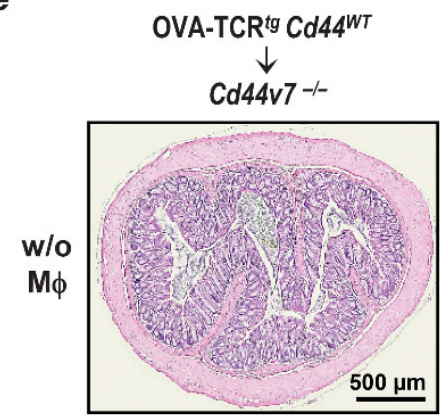

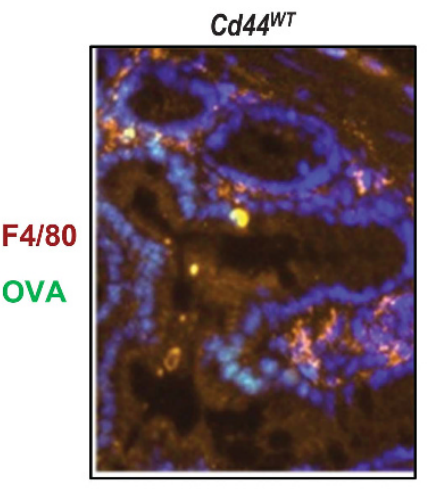

b
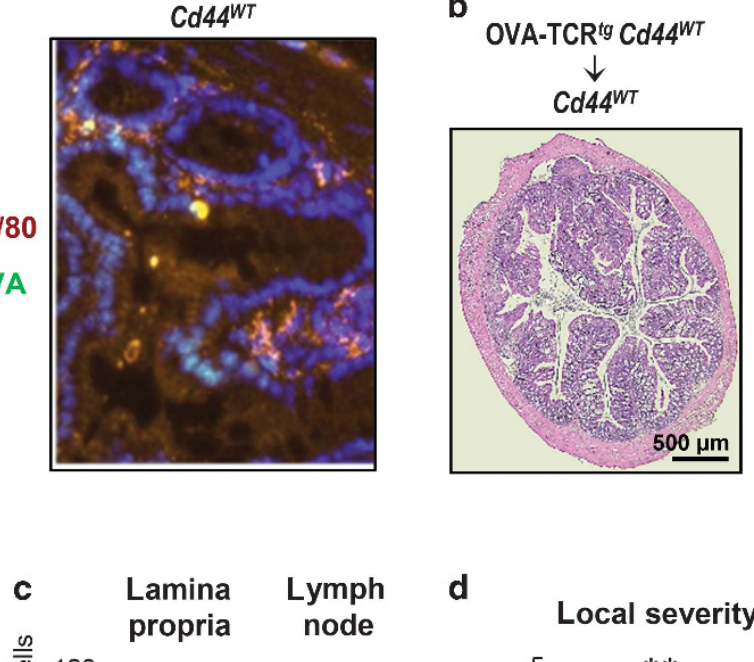

d Local severity

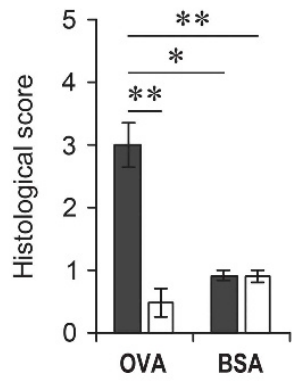

OVA-TCR ${ }^{\text {tg }} \mathrm{Cd} 44 \mathrm{v} 7^{-/-} \rightarrow \mathrm{Cd} 44^{\mathrm{WT}}$

OVA-TCR ${ }^{\text {tg }}$ Cd44WT $\rightarrow$ Cd44v7 $7^{-/-}$

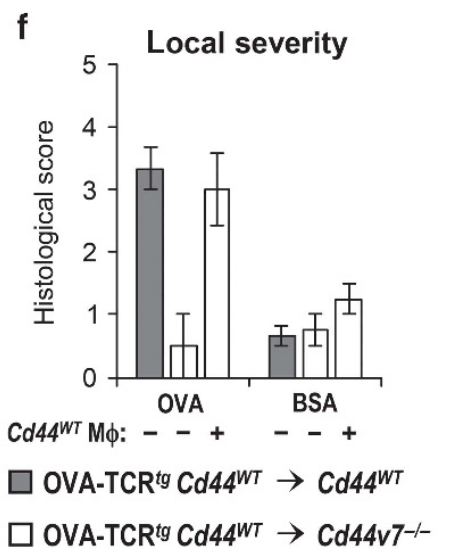

Figure $6 \quad C D 44 V 7$ on macrophages controls ovalbumin (OVA)-specific colitis. (a) fluorescein isothiocyanate (FITC)-labeled OVA peptide was applied intrarectally into $C D 44^{W T}$, OVA-TCR ${ }^{t g} C d 44^{W T}$, and OVA-TCR ${ }^{t g} C d 44 V 7^{-1-}$ mice. After 30 min mice were killed. (Left) Lamina propria mononuclear cells were isolated and analyzed by flow cytometry. Representative images out of three to five mice per genotype are shown. (Right) Immunofluorescent staining of colon sections was performed by use of $4^{\prime}, 6$-diamidino-2-phenylindole (DAPI) and rat anti-mouse F4/80 antibody (DAPI: blue; OVA: green; macrophages: red). (b-d) $C d 44^{W T}$ and $C d 44 V 7^{-1-}$ recipients were injected intraperitoneally (i.p.) with $1 \times 10^{7} \mathrm{~T}$-helper type 1 (Th1) cells derived from

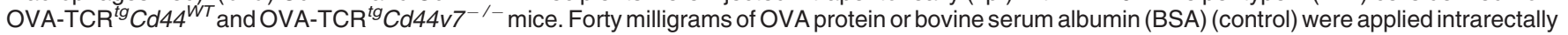
at days 1 and 4, and colons, lamina propria, and mesenteric lymph nodes were prepared at day 7. (b) Hematoxylin and eosin (H\&E) staining of frozen colon sections was performed (one representative section out of three to five OVA-injected mice per group is shown; bar $=500 \mu \mathrm{m}$ ). (c) Quantity of $\mathrm{CD} 4^{+}$OVA-TCR ${ }^{\text {tg }}$ cells was analyzed by flow cytometry. Data from eight to ten mice per group per $10^{5}$ assessed cells are given as mean $\pm \mathrm{s}$.e.m. (d) Histology was graded from 0 (no inflammation) to 4 (extended cell infiltrates, ulcerations). Data from three to five mice per group are given as mean \pm s.e.m. (e and f) $C d 44 v 7^{-/-}$mice were injected i.p. with $1 \times 10^{7}$ Th1 cells derived from OVA-TCR ${ }^{\text {tg }} C d 44^{W T}$ mice with or without $2 \times 10^{5}$ macrophages $(\mathrm{M} \phi)$ from $C d 44^{W T}$ mice. Forty milligrams of OVA protein or BSA (control) was applied intrarectally at days 1 and 4 , and colons were prepared at day 7. (e) H\&E staining of frozen colon sections was performed (one representative section out of two to three OVA-injected mice per group is shown; bar-500 um). (f) Histological scores from two to three mice per group are given as mean \pm s.e.m. ${ }^{*} P \leq 0.05$; ${ }^{* *} P \leq 0.01$ (Mann-Whitney $U$-test, twotailed). 
a

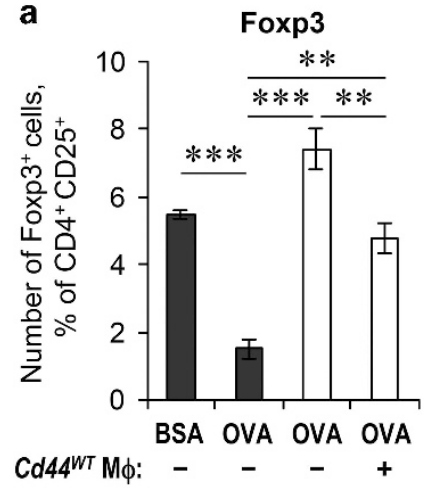

OVA-TCR ${ }^{\operatorname{tg}}$ Cd44 $4^{W T} \rightarrow$ Cd44 $4^{W T}$ $\square$ OVA-TCR ${ }^{\text {tg }} \mathrm{Cd} 44^{W T} \rightarrow \mathrm{Cd} 44 \mathrm{v} 7^{-/-}$

Figure 7 CD44v7 on macrophages hampers Foxp3 expression in vivo and in vitro. (a) $C d 44^{W T}$ and $C d 44 v 7^{-1-}$ recipients were injected intraperitoneally (i.p.) with $1 \times 10^{7} \mathrm{~T}$-helper type 1 (Th1) cells derived from ovalbumin (OVA)-TCR ${ }^{\text {tg }} \mathrm{Cd} 44^{W T}$ with or without $2 \times 10^{5}$ macrophages $(\mathrm{M} \phi)$ from $C d 44^{W T}$ mice. Forty milligrams OVA protein or bovine serum albumin (BSA) (control) was applied intrarectally at days 1 and 4, and lamina propria was prepared at day 7 . The number of Foxp3 ${ }^{+}$cells was analyzed by flow cytometry. Data from four to six mice per group are given as percent of $\mathrm{CD} 4{ }^{+} \mathrm{CD} 25^{+}$within $\mathrm{CD} 4{ }^{+}$lamina propria cells (mean \pm s.e.m.). (b) T cells and macrophages $(M \phi)$ isolated from spleen and lymph nodes of $C d 44^{W T}$ and $C d 44 v 7^{-1-}$ mice, were cocultured at a ratio of $1: 3$, stimulated with anti-CD3 coated on the culture vessel and restimulated with OVA peptide $(5 \mu \mathrm{g} / \mathrm{ml})$ or BSA (control) as indicated for 6 days. Foxp3 gene expression was analyzed relative to mouse glyceraldehyde 3-phosphate dehydrogenase (GAPDH) expression by quantitative PCR (qPCR). Data from five to six independent experiments (mean \pm s.e.m.) are given as the fold difference to BSA-treated group. ${ }^{* \star} P \leq 0.01 ;{ }^{* * *} P \leq 0.001$ (Mann-Whitney $U$-test, two-tailed).

TNF- $\alpha$ blockers ( $\alpha$ TNF- $\alpha$, Crohn's disease activity index: $248.3 \pm 24.7$; antimetabolites, Crohn's disease activity index: $349.5 \pm 40.5 ; P=0.063)$.

\section{DISCUSSION}

We demonstrate that the deletion of a single variant exon, namely $v 7$, in the $C d 44$ gene of recipient animals leads to strongly reduced intestinal inflammation in T-cell-dependent colitis. This is probably the consequence of elevated numbers of iTreg cells and diminished expression of Th1-cell effector cytokines in the colon of these mice. Remarkably, cotransfer of a small number of $C d 44^{W T}$ macrophages together with the $\mathrm{T}$ cells prevented the increase in iTreg cells and evoked colon inflammation in the $C d 44 v 7^{-1-}$ recipients. Matching our in vivo data, induction of lymphocyte Foxp3 was triggered by $v 7^{-/-}$macrophages, but not by $C d 44^{W T}$ macrophages in vitro.

Our present data and the recent discoveries from other working groups suggest the following initial step of a respective cascade: during inflammation, the interaction between OPN and v7-containing CD44 isoforms expressed on monocytic cells enhances IL-6 secretion. In fact, we observed (i) elevated OPN blood levels in Crohn's disease patients, (ii) strong CD44v7 expression in monocytic cells but not in T-cell subpopulations, and (iii) a substantial OPN-induced production of IL-6 by monocytic cells but not by T-cell sub-populations.

Furthermore, it has been shown that this small part of the CD44 molecule (v7 with 42 amino acids) is important for OPN binding of respective CD44 isoforms ${ }^{29}$ and we observed CD44v7 dependence of OPN-induced IL- 6 production by monocytic cells. Accordantly, we detected $\sim 30$ and 10 times increased IL-6 and IL-27 levels, respectively, in the colon mucosa of $C d 44^{W T}$ compared withCd $44 v 7^{-/-}$transfer recipients. IL-6 and IL-27 exert their effects through activation of STAT3 ${ }^{26,30}$ Concordantly, we found approximately four times lower number of lymphocytes containing phosphorylated STAT3 in the mucosal infiltrates of $C d 44 v 7^{-/-}$mice in comparison with $C d 44^{W T}$ transfer recipients. Activation of STAT3 in T cells inhibits their development into iTreg cells. ${ }^{31}$ Consistently, both IL-6 (ref. ${ }^{32}$ ) and IL-27 (ref. ${ }^{33}$ ) suppress Foxp $3^{+}$induction in T cells and prevent iTreg cell development. This effect is functionally relevant since the absence of each of these cytokines reduces colonic inflammation in a T-cell transfer colitis model. ${ }^{33-35}$ These findings are fully coherent with our data showing significantly higher numbers $(\sim 5$-fold $)$ of Foxp3 ${ }^{+} \mathrm{T}$ cells in the lamina propria of $C d 44 v 7^{-1-}$ compared with $C d 44^{W T}$ transfer recipients and found no signs of inflammation in $C d 44 v 7^{-1-}$ mice. The strong colonic presence of iTreg cells in $C d 44 v 7^{-/-}$transfer recipients might have led to the reduced production of $\mathrm{T}$-cell-activating cytokines. The absence of these mediators and the presence of iTreg cells in turn seem to be the cause for the diminished expression of IFN- $\gamma$ by T cells in the lamina propria. Finally, the presence (in $C d 44^{W T}$ mice) and absence (in $C d 44 v 7^{-1-}$ mice) of IFN- $\gamma$ determines a distinct intestinal pathology, as strongly supported by studies of Powrie et al. ${ }^{16}$ as well as Ito and Fathman, ${ }^{19}$ who demonstrated ameliorated colitis in the CD45RB hi $\mathrm{T}$-cell transfer model when recipient mice were treated with IFN- $\gamma$-neutralizing antibodies or the transferred CD45RB hi $\mathrm{T}$ cells were isolated from IFN- $\gamma$-deficient mice.

The proposed cascade described above comprising CD44v7, OPN, IL-10, IL-6/IL-27, STAT3, Foxp3, iTreg cells, IL-12, IL- $1 \beta$, and IFN- $\gamma$ is very probably deregulated in patients with active Crohn's disease and hence has clinical importance. In such patients, we detected increased OPN serum concentrations as mentioned above, and these correlated with clinical disease activity. ${ }^{14}$ Interestingly, patients suffering from psoriasis, another common chronic inflammatory disease, did not have elevated blood OPN levels. In Crohn's disease patients, blood OPN levels did not correlate with the duration of the disease, suggesting that the OPN increase in these patients is not associated with chronification of the inflammation. Instead, these facts propose the CD44v7/OPN cascade as being a rather basic alteration in Crohn's disease. Moreover, lower blood OPN levels were observed in Crohn's disease patients treated with TNF- $\alpha$-blocking agents compared to those treated with classical antimetabolites supporting the known role of TNF- $\alpha$ as a driver of OPN production. ${ }^{28}$ Additionally, this suggests that the CD44v7/OPN cascade is not normalized upon classical treatments. This is in line with the clinical observation in patients with active disease that symptoms rapidly reoccur after stop of antimetabolite application. Furthermore, we 

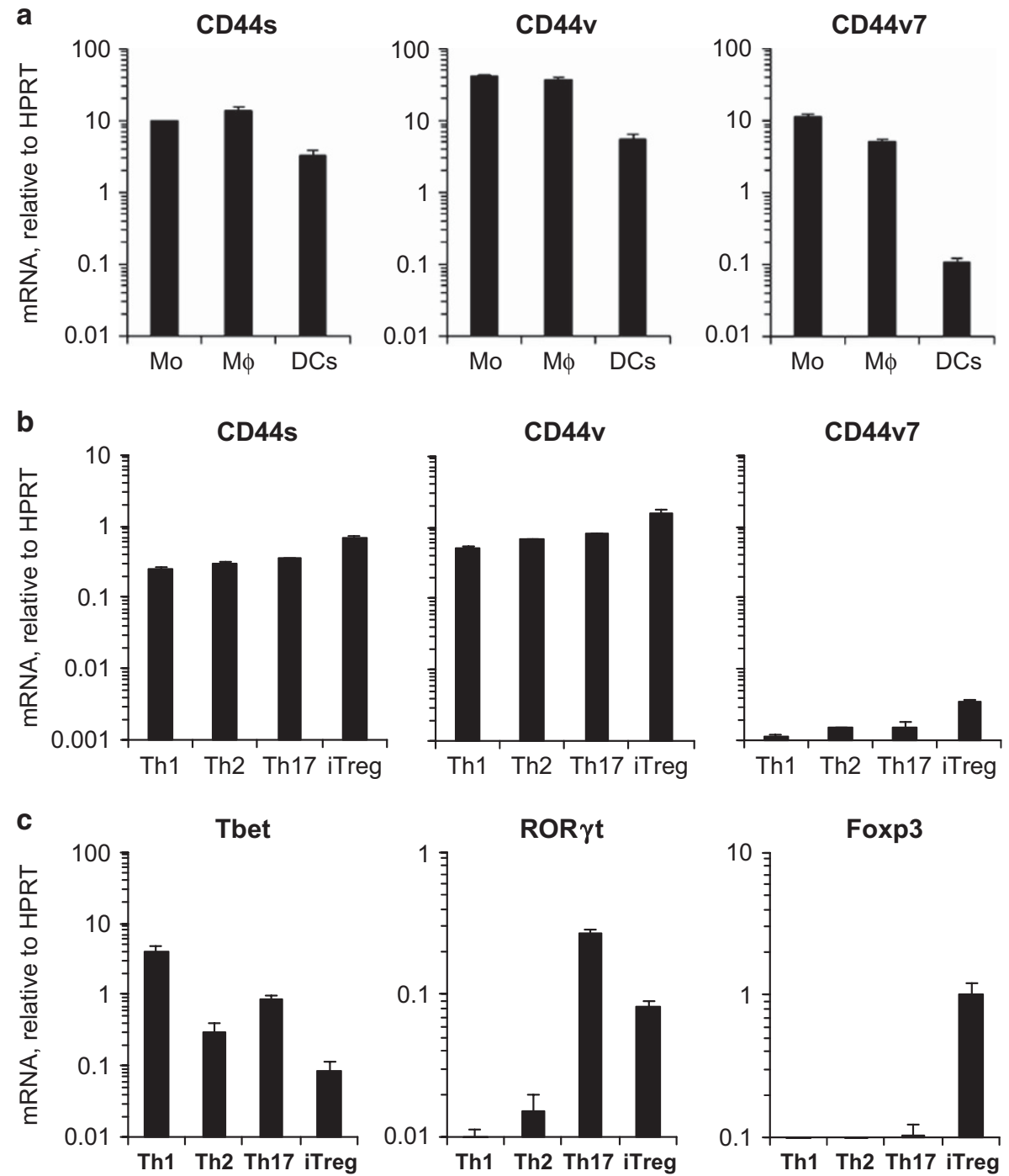

Figure 8 Human macrophages show high expression of CD44v7. (a) Human monocytes (Mo) were isolated from peripheral blood mononuclear cells (PBMCs) by a magnet-based system and differentiated into either macrophages (M $\phi)$ or dendritic cells (DCs) by a 6-day culture in the presence of macrophage colony-stimulating factor (M-CSF) (M $\phi)$ or Granulocyte-macrophage colony-stimulating factor (GM-CSF) and interleukin-4 (IL-4) (DC), respectively. DCs were then matured in the presence of tumor necrosis factor- $\alpha$ (TNF- $\alpha$ and IL-1 $\beta$ ) for further 2 days. Subsequently, Mo as well as

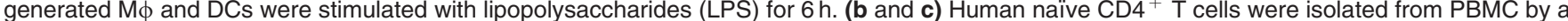
magnet-based system and differentiated intro T-helper type 1 (Th1), Th2, Th17, and regulatory T (Treg) cells by a 8-day culture with stimulation via CD3 and CD28 in the presence of Th subset-polarizing conditions (see Supplementary Table S2 online). Gene expression was analyzed by quantitative PCR (qPCR). Data from three (a), two (b), and three (c) independent experiments are given as mean \pm range/s.e.m.

demonstrated that OPN at concentrations similar to those found in Crohn's disease patients induced CD44v7-dependent secretion of IL-6 by human monocytic cells, putting both molecules in a direct relationship within the cascade described above. Moreover, colonic levels of IL-6, IL-12, and IFN- $\gamma$ were also shown to be elevated in patients. ${ }^{36}$ The high local production of IL-6 even results in elevated amounts of this cytokine in the bloodstream as we demonstrated. Furthermore, Crohn's disease patients exhibit a relative deficiency of IL-10, TGF- $\beta$, and Treg cells. ${ }^{37,38}$ Accordingly, we observed in vitro that IL-10 neutralization increased the OPN-induced IL- 6 production by monocytes. Finally, genome-wide association studies identified single-nucleotide polymorphisms in the STAT3 locus as one of the Crohn's disease susceptibility regions. ${ }^{39,40}$
Nevertheless, we would like to mention that the association between IL- 6 deficiency and iTreg cells abundance may not be the only reasons for the effect of CD44v7 deficiency. It might be possible that $C D 44 v 7^{-1-}$ macrophages exert inhibitory effects on effector $\mathrm{T}$ cells independent of iTreg cells by, e.g., reduced IL-1 $\beta /$ IL-12 production and/or elevated secretion of inhibitory IL-10.

Another $C d 44$ genomic region targeted in our study was the variant exon $v 10$ that represents an internal study control because it is expressed in virtually all CD44 isoforms that contain variant regions. In contrast to $C D 44 v 7^{-/-}$recipients, $C D 44 v 10^{-/-}$mice became as severely ill as the $C d 44^{W T}$ mice. CD44v10 ${ }^{-/-}$transfer recipients showed high IL-6 and IL-27 expression, abundant STAT3 activation, small iTreg cell 
a

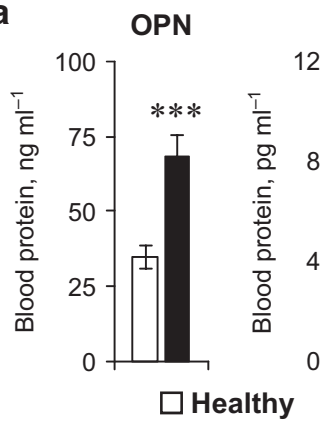

IL-6

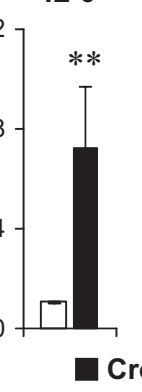

IL-1 $\beta$

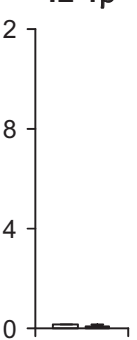

rohn's disease
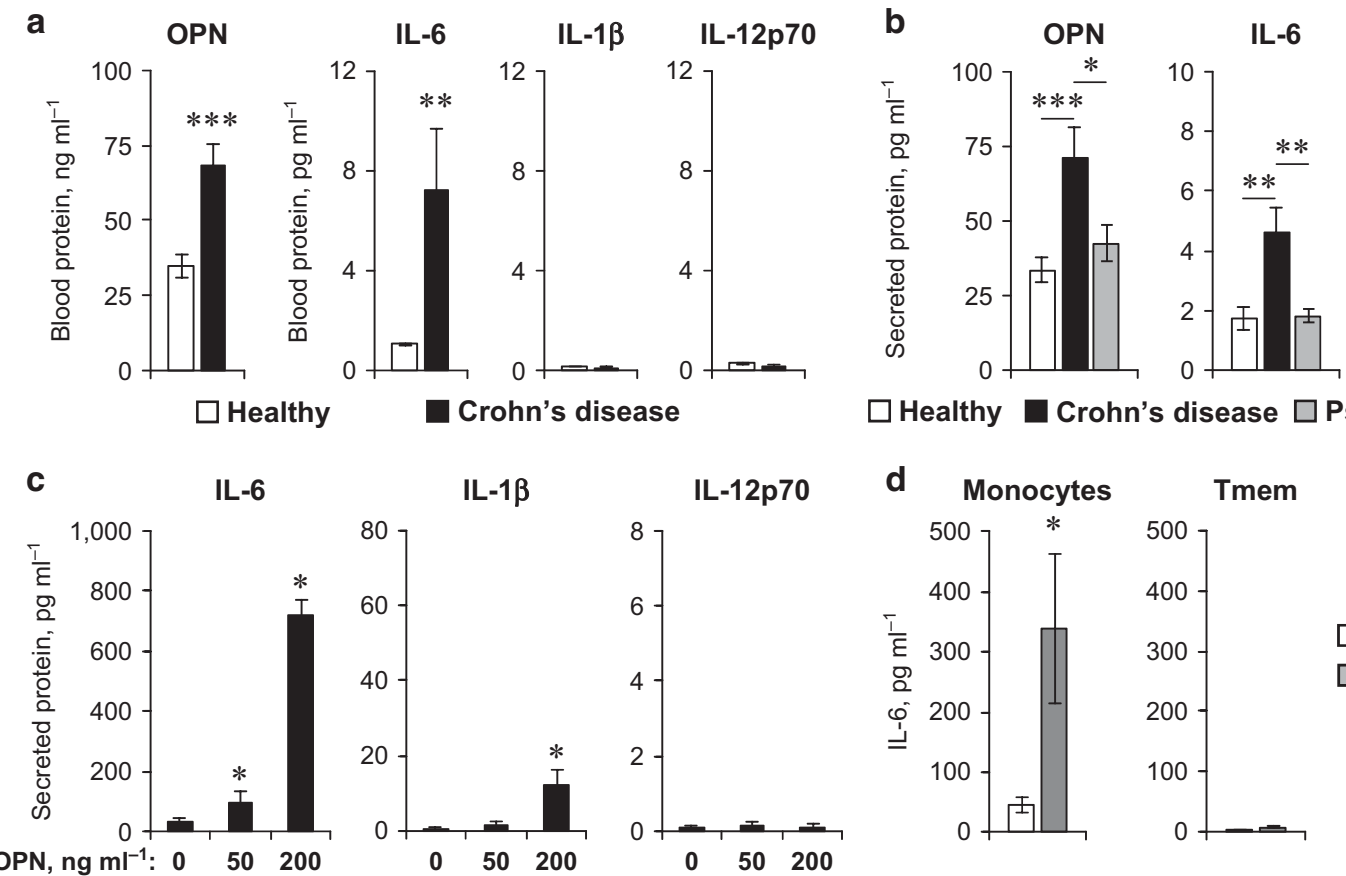

$\square$ Healthy $\square$ Crohn's disease $\square$ Psoriasis

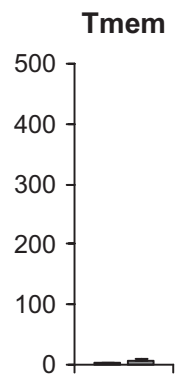

Control $\square$ OPN
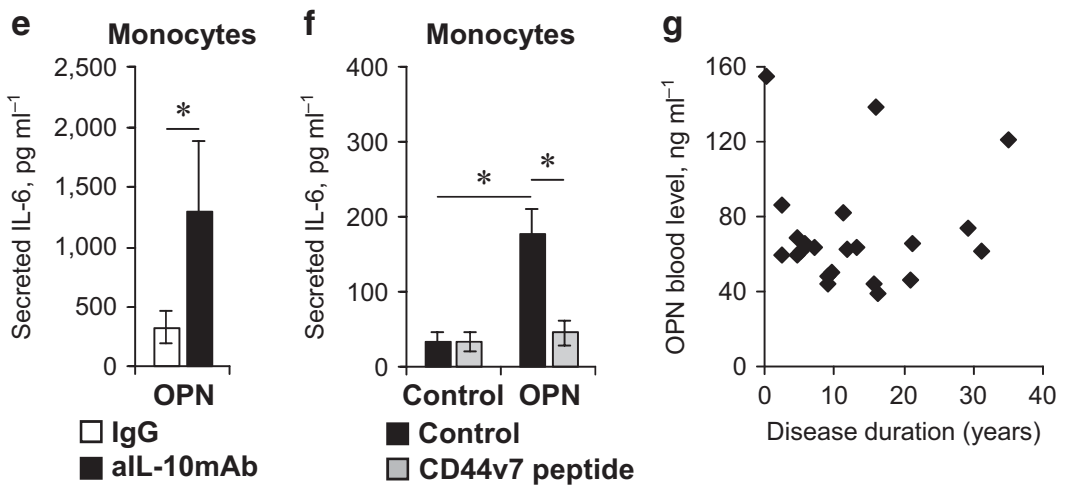

h

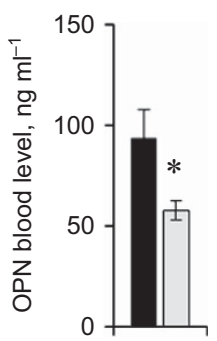

Antimetabolite Anti-TNF- $\alpha$

Figure 9 The CD44 ligand osteopontin (OPN) induces inflammatory cytokine production in human monocytes and is systemically elevated in Crohn's disease. (a) Blood plasma and serum from 12 Crohn's disease patients (cohort 1) and 12 matched healthy control individuals was analyzed by enzymelinked immunosorbent assay (ELISA). Data are given as mean \pm s.e.m. (b) Blood plasma and serum from 11 Crohn's disease patients (cohort 2), 11 psoriasis patients, and 11 healthy control individuals was analyzed by ELISA. Data are given as mean \pm s.e.m. (c) Peripheral blood mononuclear cells (PBMCs) were stimulated with increasing concentrations of OPN for $48 \mathrm{~h}$. Cell culture supernatants were analyzed for concentration of cytokines by ELISA. (d-f) Human monocytes and CD4 ${ }^{+}$memory T cells (Tmem, (d) only) were isolated from PBMC by magnet-based systems and stimulated with OPN alone (d) or in the simultaneous presence of anti-interleukin-10 (IL-10) monoclonal antibody (mAb) or immunoglobulin G (IgG) (e) or CD44v7 peptide (f) for $48 \mathrm{~h}$. Cell culture supernatants were analyzed for IL-6 concentration by ELISA. Data from six (c and e) or five (d and f) independent experiments are given as mean \pm s.e.m. (g) Blood plasma from 23 Crohn's disease patients (cohort 1 and 2 ) was analyzed by ELISA. Individual OPN concentrations were tested for correlation with disease duration of patients by Spearman's rank correlation analysis. No significant correlation was detected. (h) OPN levels detected by ELISA in the blood plasma of Crohn's disease patients (from cohort 1 and 2) treated with either anti-metabolites (methotrexate, mercaptopurine, azathioprine; seven patients) or anti-TNF- $\alpha$ drug (adalimumab, infliximab; six patients) are plotted as mean \pm s.e.m. Testing for possible significant differences between the groups was carried out by the Mann-Whitney U-test (two-tailed) (a, b, and h) or Wilcoxon's test (two-tailed) (c-f), respectively $\left({ }^{\star} P \leq 0.05 ;{ }^{\star \star} P \leq 0.01 ;{ }^{* \star \star} P \leq 0.001\right)$.

numbers, high IL-12 and IFN- $\gamma$ levels, and strong inflammation in their colons. This also supports the idea that these changes are key events in the development of the pathology in T-cell-dependent intestinal inflammation. Interestingly, in contrast to diseased $C d 44^{W T}$ but similar to healthy $C D 44 v 7^{-1-}$, we detected very low levels of IL-17A, IL-17F, and IL-22 in colons of $C D 44 v_{10} 0^{-1-}$ transfer recipients. This might imply that these mediators do not play a key role in the maintenance of colitis. The discovery from the Mizoguchi group and our own work of the protective role of IL-22 in colitis ${ }^{22,41}$ even suggests

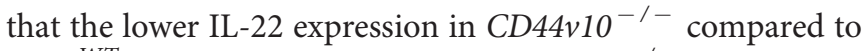
$C d 44^{W T}$ was actually the cause why $C D 44 v 10^{-/-}$mice were as severely ill as the $C d 44^{W T}$ mice.

Interestingly, the deletion of $C D 44 v 7$ in transferred $\mathrm{T}$ cells neither abrogated intestinal inflammation in $\mathrm{RB}^{\text {hi }}$ T-cell transfer colitis nor in OVA antigen-specific colitis. This means that the prevention of $\mathrm{v} 7$-involving CD44 signaling in lymphocytes, known to provoke in some situations elevated activation-induced cell death rates by downregulation of antiapoptotic Bcl-2 and Bcl-xL, ${ }^{42-44}$ is incapable of abrogating 
the intestinal inflammation in these two mouse models in vivo.

In summary, our data from two T-cell-dependent colon inflammation models show that the expression of $\mathrm{v} 7$-containing CD44 isoforms on macrophages, but not on $\mathrm{T}$ cells, is essential for provoking chronic colitis in mice. By suggesting the mechanism underlying CD44v7-dependent gastrointestinal inflammation, our study not only provides novel insight into its pathogenetic cascade but also hints to novel therapeutic strategies. In fact, we suggest $\mathrm{CD} 44 \mathrm{v} 7$ as a primary target molecule whose inhibition might be more effective than, e.g., IL-6 targeting. Actually, the blockade of IL-6 activity via application of anti-IL-6R antibody (tocilizumab) and anti-IL-6 antibody (PF-04236921) showed only limited clinical response in Crohn's disease patients. ${ }^{45,46}$ This might be due to the heterogeneity of IL-6 effects in colitis. In fact, IL-6 is pathogenetic due to its ability to inhibit iTreg development/ function and to enhance the generation/activation of pathogenetic effector T cells. At the same time, however, IL- 6 can act on epithelial cells, inducing antiapoptotic proteins such as Bcl$\mathrm{x}(\mathrm{L})$ and $\mathrm{Bcl}-3$, protecting them from apoptosis, and promoting their survival. ${ }^{47,48}$ Thus, it is not surprising that the inhibition of both IL-6 actions has only limited clinical effect. In contrast, CD44v7 targeting might reduce IL-6 production specifically by APC during their interaction with $\mathrm{T}$ cells and positively change the proportion between iTreg and pathogenetic effector $\mathrm{T}$ cells. On the other hand, the IL- 6 production by other cells like IL-1 $\beta$-activated fibroblasts and the resulting protective action on epithelial cells might be untouched. Furthermore, the OPNCD44v7 interaction altered not only the IL-6 production. In fact, the engagement of CD44v7 on macrophages by OPN was also shown to inhibit the IL-10 production. ${ }^{13}$ Consequently, a CD44v7-directed therapy is expected to be associated with a greater effectiveness and long-term clinical improvement compared with direct blockade of IL-6 activity.

\section{METHODS}

Animals. The targeted mice for the CD44 variant exons $v 7, v 6 v 7$, and $v 10^{8,49}$ were backcrossed for 10 generations onto the $\mathrm{BALB} / \mathrm{c}$ background. BALB/c mice (Iffa Credo BJico, Orléans, France) were used to backcross the targeted mutation in Rag2 for 10 generations to yield $\mathrm{BALB} / \mathrm{c}$ Rag $2^{-/-}$mice. $\operatorname{Rag} 2^{-/-}$mice with additional inactivation of CD44 variant exons were generated by respective crossing. DO11.10 transgenic (OVA-TCR ${ }^{\mathrm{tg}}$ ) mice were backcrossed for 10 generations onto the $\mathrm{BALB} / \mathrm{c}$ background to yield $\mathrm{BALB} / \mathrm{c}$ DO11.10 mice. The transgenic TCR of DO11.10 mice recognizes the 323-339 peptide of OVA in the context of $\mathrm{I}-\mathrm{A}^{\mathrm{d}}$ and is detectable with a monoclonal antibody (mAb), clone KJ1-26 (kindly provided by the German Arthritis Research Centre, Berlin, Germany). Furthermore, $C d 44 v 7^{-/-}$DO11.10 doubly targeted mice were generated. Mice were housed under SPF conditions in the animal facilities of the Basel University, Switzerland and of the Charité Berlin, Germany. All experiments were performed with age-matched animals in accordance with institutional, state, and federal guidelines.

RB $^{\text {hi }}$ T-cell transfer colitis. T-cell transfer colitis was induced in recombination-activating gene 2 -deficient $\left(R a g 2^{-1-}\right)$ mice by application of CD $4^{+} \mathrm{CD} 45 \mathrm{RB}^{\text {hi }} \mathrm{T}$ cells as established by Powrie et al ${ }^{16}$ Therefore, $\mathrm{CD} 4{ }^{+} \mathrm{CD} 45 \mathrm{RB}$ T cells from $C d 44^{W T}$ and $C d 44 v 7^{-/-}$mice were stained with an APC-labeled anti-CD4 antibody (clone RPA-T4;
BD Pharmingen, San Diego, CA) and with a PE-labeled anti-CD45RB antibody (clone 30-F11; BD Pharmingen) and sorted by FACS (MoFlo; Beckman Coulter, Krefeld, Germany). The purity was $>95 \%$. To induce $\mathrm{RB}^{\text {hi }} \mathrm{T}$-cell transfer colitis, $4 \times 10^{5} \mathrm{RB}^{\mathrm{hi}}$ with or without $2 \times 10^{5}$ $\mathrm{RB}^{\text {lo }}$ cells from $C d 44^{W T}$ or $C d 44 v 7^{-1-}$ mice were injected intraperitoneally into $\mathrm{Rag} 2^{-1-}$ mice of the four genotypes. Mice were killed at weeks 6 to 8 and the colon and mesenteric lymph nodes were excised. Shorter observation times had to be applied when the body weight reached $<70 \%$ of the original weight at start. Neutralization of CD44v6 or CD44v7 in Rag2 ${ }^{-1}$ Cd44 ${ }^{W T}$ recipient mice was carried out by intraperitoneally application of $4 \times 10^{5} \mathrm{RB}^{\mathrm{hi}}$ cells $+200 \mu \mathrm{g}$ per mouse anti-CD44v6 mAb (clone LN6.1) or $^{7} \times 10^{5} \mathrm{RB}^{\text {hi }}$ cells + $200 \mu \mathrm{g}$ per mouse anti-CD44v7 mAb (clone LN7.2). ${ }^{7}$

OVA antigen-specific colitis. Lymphocytes of $\mathrm{OVA}-\mathrm{TCR}^{\mathrm{tg}}$ mice $\left(C d 44^{W T}\right.$ or $\left.C d 44 v 7^{-/-}\right)$were primed in vitro with $5 \mu \mathrm{g} \mathrm{ml}^{-1}$ OVA peptide (residues 323-339, kindly provided by Dr. P Henklein, Institute of Biochemistry, Charité, Berlin, Germany) and $10 \mathrm{ng} \mathrm{ml}^{-1}$ IL-12 (PeproTech EC, London, UK). After 6 days, the resulting Th1 cells were purified by Ficoll (Biochrom AG, Berlin, Germany) and were 88-96 \% OVA-TCR ${ }^{+}$, as assessed by antibody staining for OVA$\mathrm{TCR}^{+}$cells. OVA-TCR ${ }^{\mathrm{tg}}$ Th1 cells $\left(1 \times 10^{7}\right.$ of $\mathrm{Cd} 44^{W T}$ or $\left.v 7^{-/-}\right)$ were injected intraperitoneally into BALB/c $C d 44^{W T}$ and $C d 44 v 7^{-1-}$ mice. At days 1 and 4 mice received $100 \mu \mathrm{l}$ ethanol (50\%) and $40 \mathrm{mg}$ OVA or BSA (control) protein intrarectally. Mice were killed at day 7.

OVA uptake by mucosal APCs was investigated in OVA$\mathrm{TCR}^{\mathrm{tg}} C d 44^{W T}$ and OVA-TCR ${ }^{\mathrm{tg}} C d 44 v 7^{-\prime-}$ mice. Fifty micrograms of FITC-labeled OVA protein (kindly provided by Prof. B Micheel, Institute of Biochemistry and Biology, University of Potsdam, Potsdam, Germany) was applied intrarectally. After $10 \mathrm{~min}$, $30 \mathrm{~min}$, and up to $18 \mathrm{~h}$ mice were killed and lamina propria mononuclear cells were isolated as described. ${ }^{8}$

Patients and healthy control donors. Blood plasma and serum were obtained from patients suffering from Crohn's disease (Supplementary Table S3) and matched psoriasis patients and control participants. For the in vitro study with PBMCs, blood plasma from an independent healthy cohort was obtained. Study protocols were approved by the institutional review boards of the Interdisciplinary Crohn Colitis Center, Minden/OWL (Crohn's disease patients) and Charité University Medicine Berlin (healthy donors and psoriasis patients).

Cell culture. Coculture of $C d 44^{W T}$-derived Th1 cells (generated as described above) and $\mathrm{M} \phi$ isolated from spleen and lymph nodes of OVA-TCR ${ }^{\mathrm{tg}} C d 44^{W T}$ and OVA-TCR ${ }^{\mathrm{tg}} C d 44 v 7^{-/-}$mice in a ratio of $1: 3$ was performed in the presence of anti-CD3 $\mathrm{mAbs}(3 \mu \mathrm{g} / \mathrm{ml}$, clone $2 \mathrm{C} 11 ; \mathrm{BD})$ coated on the culture vessel and with OVA peptide or BSA (control) (each at $5 \mu \mathrm{g} / \mathrm{ml}$ ) for 6 days.

Human PBMCs from healthy donors were isolated by density gradient centrifugation using Ficoll separation solution (Biochrom AG) and LeucoSep tubes (Greiner, Frickenhausen, Germany). To study the OPN pathway in human immune cells and human PBMCs, as well as monocytes and memory $\mathrm{T}$ cells, isolated, therefore, by magnetic cell sorting (Miltenyi Biotec, Bergisch Gladbach, Germany) were cultured in RPMI medium (Biochrom) supplemented by $2 \mathrm{mM}$ L-glutamine and 10\% fetal calf serum (both from Biochrom) in the presence of 0,50 , and $200 \mathrm{ng} / \mathrm{ml} \mathrm{OPN}$ (Peprotech EC) for $48 \mathrm{~h}$ and cell culture supernatants were recovered. Additionally, monocytes and memory T cells were cultured in the presence of anti-IL-10 mAbs (clone CB/RS2), ${ }^{50}$ IgG (isotype control), or CD44v7 peptide (manufactured as described above; OPN-CD44v7 peptide ratio $1: 10)$ during OPN stimulation for $48 \mathrm{~h}$. Before cell stimulation, OPN was preincubated with CD44v7 peptide for $4 \mathrm{~h}$ at $37^{\circ} \mathrm{C}$.

For expression analysis of transcription factors, murine $\mathrm{CD} 25^{-}$ $\mathrm{CD} 4{ }^{+} \mathrm{CD} 62 \mathrm{~L}^{\text {high }}$ naïve $\mathrm{T}$ cells were isolated from erythrocytes depleted from the spleen (lysis solution: $10 \mathrm{mM} \mathrm{KHCO}_{3}, 155 \mathrm{~mm}$ $\mathrm{NH}_{4} \mathrm{CL}, 0.1$ mM EDTA, $\mathrm{pH}$ 7.5) and lymph nodes of C57/BL6 mice by 
staining with FITC-coupled CD4 and APC-coupled CD25 mAbs (BD Pharmingen, Heidelberg, Germany), followed by magnetic cell sorting using the AutoMACS System, anti-APC microbeads, anti-FITC MultiSort Kit, and anti-CD62L microbeads (all from Miltenyi Biotec). Polarization of isolated murine naïve CD4 T cells was achieved by culturing the cells for 3 days in anti-CD3 $(4 \mu \mathrm{g} / \mathrm{ml}) / \mathrm{anti}-\mathrm{CD} 28$ $(3 \mu \mathrm{g} / \mathrm{ml}) \mathrm{mAb}$ - (produced in-house; German Rheumatism Research Center, Berlin, Germany) coated culture plates (Nunc; Thermo Fisher Scientific, Schwerte, Germany) in the presence of Th-subset-polarizing conditions (Supplementary Table S1). Subsequently, cells were recultured for further $24 \mathrm{~h}$ in the presence of Th-subtypepolarizing conditions (see above) in the absence of CD3/CD28 antibodies. In a further setting iTregs were treated during their differentiation with $1 \mu \mathrm{M}$ LE540, a chemical pan-RAR antagonist (Wako Pure Chemical Industries, Osaka, Japan).

To compare transcription factor expression level in human Th cell subtypes, naive $\mathrm{CD} 4^{+} \mathrm{T}$ cells were isolated from the PBMC using the "Naïve CD4 ${ }^{+}$T-cell Isolation /Kit II" (Miltenyi Biotec). Obtained purities of $\mathrm{CD}^{+}{ }^{+} \mathrm{CD} 45 \mathrm{RA}{ }^{+}$cells were $95.9 \pm 0.9 \%$. Cells were stimulated for 8 days by anti-CD3/anti-CD28 antibody-coated Dynabeads (Invitrogen, Life Technologies, Darmstadt, Germany) in the presence of Th-subset-polarizing conditions (Supplementary Table S2) as described previously. ${ }^{51}$

Histology and immunohistology. Histological scoring of segments of the distal, transverse, and proximal colon was performed using a previously established score reference for the transfer model and an adapted score for the OVA-specific colitis. The latter is a score of 0-4 for epithelial loss and inflammatory infiltration (0: no changes; 1 : isolated cell infiltrates within the mucosa; 2: diffuse cell infiltrates within mucosa and submucosa, mild epithelial hyperplasia; 3: cell infiltrates within mucosa, submucosa, and transmural epithelial hyperplasia; 4: severe inflammation, loss of crypts, ulceration, severe epithelial hyperplasia). For immunohistological analysis, fixed sections $(5 \mu \mathrm{m})$ were stained with the following antibodies: anti-CD4 (clone RM4-5; BD Pharmingen), anti-Foxp3 (clone FJK-16s; eBioscience, NatuTec, Frankfurt, Germany), anti-pSTAT3 (Tyr705) (clone D3A7; Cell Signaling, Danvers, MA), and corresponding isotype-matched antibodies (rabbit IgG and rat IgG2a; BD Pharmingen). The used secondary antibodies were goat anti-rabbit IgG (Vectastain ABC Kit, Reactolab, Servion, Switzerland) or goat anti-rat IgG H\&L (Southern Biotech; Birmingham, AL, 3010-08). For visualization the ABC System (Vectastain ABC Kit) with AEC was chosen. Numerical analyses of colon sections were performed by counting 1536 fields at a final magnification of $\times 200\left(\right.$ Foxp3; $\left.1.33 \mathrm{~mm}^{2}\right)$ or by evaluating positive cells/1,000 lymphocytes (pSTAT3).

SUPPLEMENTARY MATERIAL is linked to the online version of the paper at http://www.nature.com/mi

\section{ACKNOWLEDGMENTS}

Dr. Inti Zlobec (Pathology Basel) kindly assisted in statistical evaluations. We thank Britt Johansson, Tanja Uhle, Brigitte Ketel, and Annette Buss for expert technical assistance. This work has been supported by the Deutsche Forschungsgemeinschaft (SFB633 TPB4) (BMW). Work in the group of J.D.L is supported by the Dutch MS Research Foundation.

\section{DISCLOSURE}

The authors declare no conflict of interest.

\section{Author contributions}

B.M.W., U.H.: designed and performed experiments (RB ${ }^{\text {hi }}$ T-cell transfer colitis, OVA antigen-specific colitis, in vitro murine Th1 cell/ macrophages coculture), and analyzed respective data. P.H., K.H., C.L.: designed and performed experiments (OVA antigen-specific colitis, in vitro murine Th1 cell / macrophages co-culture), and analyzed respective data. C.S., H.K.: designed and performed experiments ( $\mathrm{RB}^{\text {hi }} \mathrm{T}$-cell transfer colitis), and analyzed respective data; U.G.: generated BALB/c Cd44v ${ }^{-1-}$ Rag2 $2^{-1-}$ and $\mathrm{Cd} 44 \mathrm{v} 7^{-/-} \mathrm{DO} 11.10$ mice, designed and performed experiments (RBhi T-cell transfer colitis), performed immunohistological analyses (CD4, Foxp3, pSTAT3), and analyzed respective data. A.T., J.D.L., L.T.: analyzed data from RBhi T-cell transfer colitis model, and contributed reagents/ materials/analysis tools. R.S., K.Wo, E.W.-H., K.Wi: designed and performed experiments (in vitro experiments using human cells), and performed analyses of human samples and mRNA expression analyses of murine tissue samples. J.T.: generated murine Th cell sub-populations. RV: synthetized CD44v7 peptide. B.B.: collected human sera from CD patients, and characterized clinical status.

\section{DISCLOSURE}

The authors declare no conflict of interest.

(c) 2018 Society for Mucosal Immunology

\section{REFERENCES}

1. Garrett, W. S., Gordon, J. I. \& Glimcher, L. H. Homeostasis and inflammation in the intestine. Cell 140, 859-870 (2010).

2. Maloy, K. J. \& Powrie, F. Intestinal homeostasis and its breakdown in inflammatory bowel disease. Nature 474, 298-306 (2011).

3. Mukherjee, S. \& Hooper, L. V. Antimicrobial defense of the intestine. Immunity 42, 28-39 (2015).

4. Khor, B., Gardet, A. \& Xavier, R. J. Genetics and pathogenesis of inflammatory bowel disease. Nature 474, 307-317 (2011).

5. Neurath, M. F. New targets for mucosal healing and therapy in inflammatory bowel diseases. Mucosal Immunol. 7, 6-19 (2014).

6. Strober, W. \& Fuss, I. J. Proinflammatory cytokines in the pathogenesis of inflammatory bowel diseases. Gastroenterology 140, 1756-1767 (2011).

7. Wittig, B., Schwärzler, C., Föhr, N., Günthert, U. \& Zöller, M. Curative treatment of an experimentally induced colitis by a CD44 variant V7specific antibody. J. Immunol. 161, 1069-1073 (1998).

8. Wittig, B. M., Johansson, B., Zöller, M., Schwärzler, C. \& Günthert, U. Abrogation of experimental colitis correlates with increased apoptosis in mice deficient for CD44 variant exon 7 (CD44v7). J. Exp. Med. 191, 20532064 (2000).

9. Günthert, C. CD44. In Encyclopedia of Cancer, 4th edn (Schwab, M., ed14) (Springer, Berlin -Heidelberg, Vol 2, pp) 851-853 (2015).

10. Johnson, P. \& Ruffell, B. CD44 and its role in inflammation and inflammatory diseases. Inflamm. Allergy Drug Targets 8, 208-220 (2009).

11. Jordan, A. R., Racine, R. R., Hennig, M. J. \& Lokeshwar, V. B. The role of CD44 in disease pathophysiology and targeted treatment. Front. Immunol. 6, 182 (2015).

12. Zöller, M. CD44, hyaluronan, the hematopoietic stem cell, and leukemiainitiating cells. Front. Immunol. 6, 235 (2015).

13. Ashkar, S. et al. Eta-1 (osteopontin): an early component of type-1 (cellmediated) immunity. Science 287, 860-864 (2000).

14. Heilmann, K. et al. Osteopontin as two-sided mediator of intestinal inflammation. J. Cell. Mol. Med. 13, 1161-1174 (2008).

15. Nedvetzki, S. et al. RHAMM, a receptor for hyaluronan-mediated motility, compensates for CD44 in inflamed CD44-knockout mice: a different interpretation of redundancy. Proc. Natl Acad .Sci. USA 101, 1808118086 (2004).

16. Powrie, F., Leach, M. W., Mauze, S., Menon, S., Caddle, L. B. \& Coffman, R. L. Inhibition of Th1 responses prevents inflammatory bowel disease in scid mice reconstituted with CD45RBhi CD4 + T cells. Immunity 1, 553562 (1994).

17. Mottet, C., Uhlig, H. H. \& Powrie, F. Cutting edge: cure of colitis by CD4 + CD25 + regulatory T cells. J. Immunol. 170, 3939-3943 (2003).

18. Shreedhar, V., Moodycliffe, A. M., Ullich, S. E., Bucana, C., Kripke, M. L. \& Flores-Romo, L. Dendritic cells require $T$ cells for functional maturation in vivo. Immunity 11, 625-636 (1999).

19. Ito, H. \& Fathman, C. G. CD45RBhigh CD4 + T cells from IFN-gamma knockout mice do not induce wasting disease. J. Autoimmun. 10, 455-459 (1997).

20. Feng, T., Qin, H., Wang, L., Benveniste, E. N., Elson, C. O. \& Cong, Y. Th17 cells induce colitis and promote Th1 cell responses through IL-17 
induction of innate IL-12 and IL-23 production. J. Immunol. 186, 63136318 (2011).

21. Sonnenberg, G. F., Fouser, L. A. \& Artis, D. Border patrol: regulation of immunity, inflammation and tissue homeostasis at barrier surfaces by IL22. Nat. Immunol. 12, 383-390 (2011).

22. Sugimoto, $\mathrm{K}$. et al. IL-22 ameliorates intestinal inflammation in a mouse model of ulcerative colitis. J. Clin. Invest. 118, 534-544 (2008).

23. Wolk, K. et al. IL-22 regulates the expression of genes responsible for antimicrobial defense, cellular differentiation, and mobility in keratinocytes: a potential role in psoriasis. Eur. J. Immunol. 36, 13091323 (2006).

24. Manel, N., Unutmaz, D. \& Littman, D. R. The differentiation of human $T(H)-17$ cells requires transforming growth factor-beta and induction of the nuclear receptor RORgammat. Nat. Immunol. 9, 641-649 (2008).

25. Mucida, D. et al. Reciprocal TH17 and regulatory $\mathrm{T}$ cell differentiation mediated by retinoic acid. Science 317, 256-260 (2007).

26. Yang, X. O. et al. Molecular antagonism and plasticity of regulatory and inflammatory T cell programs. Immunity 29, 44-56 (2008).

27. Capsoni, F., Minonzio, F., Mariani, C., Ongari, A. M., Bonara, P. \& Fiorelli, G. Development of phagocytic function of cultured human monocytes is regulated by cell surface IL-10. Cell Immunol. 189, 5159 (1998).

28. Miyazaki, Y. etal. Expression of osteopontin in a macrophage cell line and in transgenic mice with pulmonary fibrosis resulting from the lung expression of a tumor necrosis factor-alpha transgene. Ann. NY Acad. Sci. 760, 334341 (1995).

29. Katagiri, Y. U. et al. CD44 variants but not CD44s cooperate with beta1containing integrins to permit cells to bind to osteopontin independently of arginine-glycine-aspartic acid, thereby stimulating cell motility and chemotaxis. Cancer Res. 59, 219-226 (1999).

30. Huber, M. et al. IL-27 inhibits the development of regulatory T cells via STAT3. Int. Immunol. 20, 223-234 (2008).

31. Durant, L. et al. Diverse targets of the transcription factor STAT3 contribute to T cell pathogenicity and homeostasis. Immunity 32, 605-615 (2010).

32. Mudter, J. \& Neurath, M. F. II-6 signaling in inflammatory bowel disease: pathophysiological role and clinical relevance. Inflamm. Bowel Dis. 13, 1016-1023 (2007).

33. Cox, J. H., Kljavin, N. M., Ramamoorthi, N., Diehl, L., Batten, M. \& Ghilardi, N. IL-27 promotes T cell-dependent colitis through multiple mechanisms. J. Exp. Med. 208, 115-123 (2011).

34. Yamamoto, M., Yoshizaki, K., Kishimoto, T. \& Ito, H. IL-6 is required for the development of Th1 cell-mediated murine colitis. J. Immunol. 164, 48784882 (2000).

35. Fujimoto, M. et al. The influence of excessive IL-6 production in vivo on the development and function of Foxp3 + regulatory Tcells. J. Immunol. 186, 32-40 (2011).
36. Strober, W., Zhang, F., Kitani, A., Fuss, I. \& Fichtner-Feigl, S. Proinflammatory cytokines underlying the inflammation of Crohn's disease. Curr. Opin. Gastroenterol. 26, 310-317 (2010).

37. Correa, I. et al. Defective IL-10 production in severe phenotypes of Crohn's disease. J. Leukoc. Biol. 85, 896-903 (2009).

38. Di Sabatino, A. et al. Peripheral regulatory T cells and serum transforming growth factor-beta: relationship with clinical response to infliximab in Crohn's disease. Inflamm. Bowel Dis. 16, 1891-1897 (2010).

39. Cenit, M. C. et al. STAT3 locus in inflammatory bowel disease and multiple sclerosis susceptibility. Genes Immun. 11, 264-268 (2010).

40. Pal, L. R. \& Moult, J. Genetic basis of common human disease: insight into the role of missense SNPs from genome-wide association studies. J. Mol. Biol. 427, 2271-2289 (2015).

41. Wolk, K. et al. IL-22 induces lipopolysaccharide-binding protein in hepatocytes: a potential systemic role of IL-22 in Crohn's disease. J. Immunol. 178, 5973-5981 (2007).

42. Baaten, B. J., Li, C. R., Deiro, M. F., Lin, M. M., Linton, P. J. \& Bradley, L. M. CD44 regulates survival and memory development in Th1 cells. Immunity 32, 104-115 (2010).

43. Hoffmann, U. et al. CD44v7 ligation downregulates the inflammatory immune response in Crohn's disease patients by apoptosis induction in mononuclear cells from the lamina propria. Cell Death Differ. 14, 15421551 (2007).

44. Marhaba, R., Bourouba, M. \& Zoller, M. CD44v7 interferes with activationinduced cell death by up-regulation of anti-apoptotic gene expression. J. Leukoc. Biol. 74, 135-148 (2003).

45. Furfaro, F., Fiorino, G., Allocca, M., Gilardi, D. \& Danese, S. Emerging therapeutic targets and strategies in Crohn's disease. Expert Rev. Gastroenterol. Hepatol. 10, 735-744 (2016).

46. Ito, H. Treatment of Crohn's disease with anti-IL-6 receptor antibody. J. Gastroenterol. 40 (Suppl 16), 32-34 (2005).

47. Dann, S. M. et al. IL-6-dependent mucosal protection prevents establishment of a microbial niche for attaching/effacing lesion-forming enteric bacterial pathogens. J. Immunol. 180, 6816-6826 (2008).

48. Grivennikov, S. et al. IL-6 and Stat3 are required for survival of intestinal epithelial cells and development of colitis-associated cancer. Cancer Cell. 15, 103-113 (2009).

49. Ghazi-Visser, L. et al. CD44 variant isoforms control experimental autoimmune encephalomyelitis by affecting the lifespan of the pathogenic T cells. FASEB J. 27, 3683-3701 (2013).

50. Sabat, R., Seifert, M., Volk, H. D. \& Glaser, R. W. Neutralizing murine monoclonal anti-interleukin-10 antibodies enhance binding of antibodies against a different epitope. Mol. Immunol. 33, 1103-1111 (1996).

51. Wolk, K. et al. IL-29 is produced by $T(H) 17$ cells and mediates the cutaneous antiviral competence in psoriasis. Sci. Transl. Med. 5, 204 ra129 (2013). 